\title{
GLOBAL WARMING - CAUSES, EFFECTS AND SOLUTION'S TRIALS
}

\section{Dr. Somaya AbouelfadI}

Associate professor - College of Engineering Architecture departmentAssuit University

\section{(Received February 19, 2012 Accepted April 9, 2012)}

This research studies the global warming problem- resources, effects and solutions. The resources are resembled in the green house gas emissions and the share of different regions in them. The effects on the world in general are resembled in threats of land losses for low level areas beside or near water, climatic emigration, diseases spread in different areas etc., For the Arab region the threat of coastal areas under sea water accompanied with the necessity of rehabilitation of big numbers of people who will lose their homes, works, lands..etc especially in Nile delta region. The research shows some strategies and projects to reduce the global warming problem and its effects. One strategy is to capture of green house gas emissions, one of the projects is the biggest solar project in the world in the great Sahara. Other projects are renewable energy projects in the Arab world and projects to reduce the global warming effects especially on Egypt. The research mentions some international agreements around this subject and suggests some marks on the way of solution.

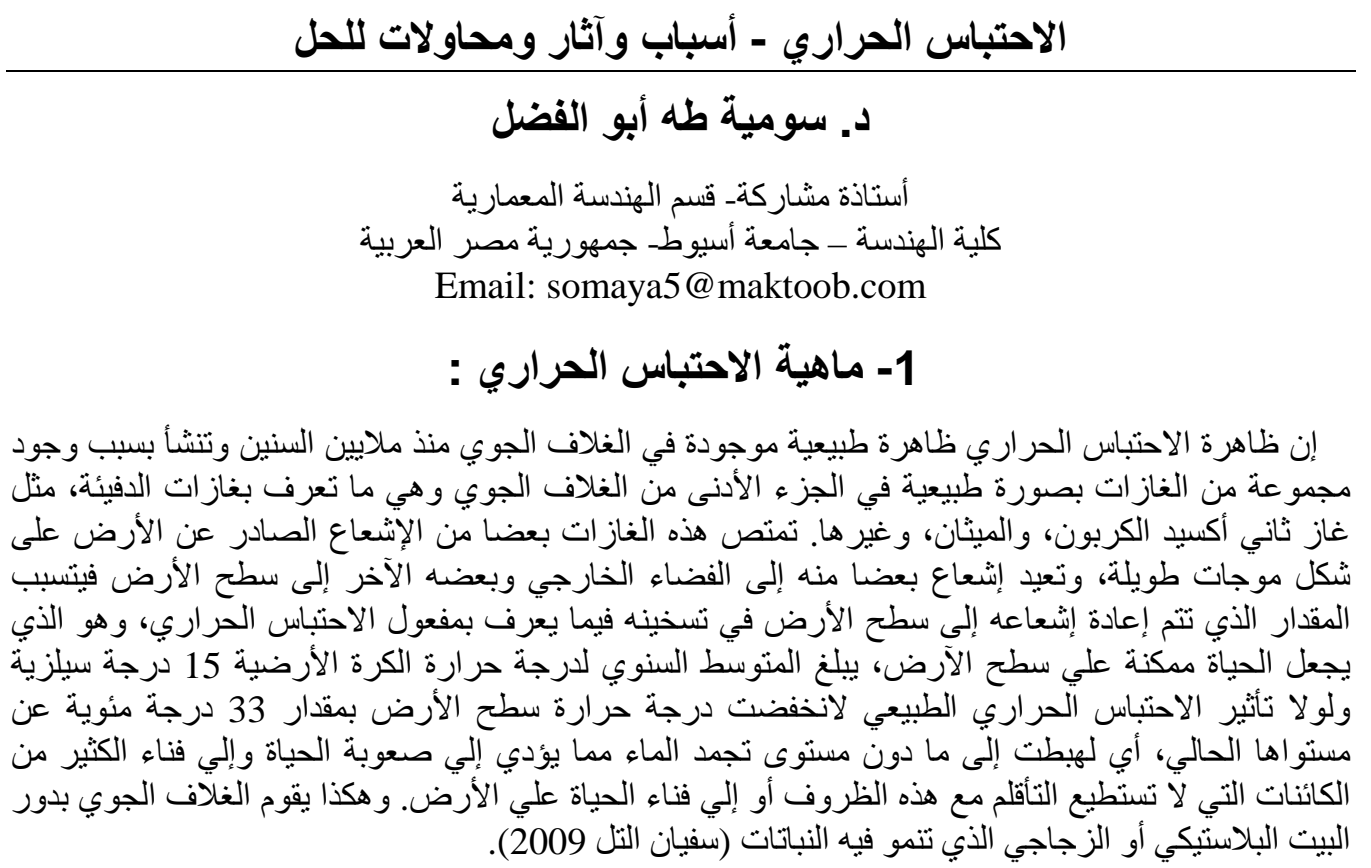




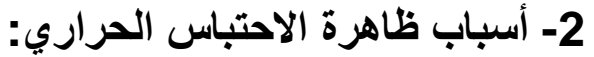

ولكي تحافظ الكرة الأرضية على اتزان حرارتها لا بد لها من أن تشع إلى الفضاء الخارجي كمية الطاقة

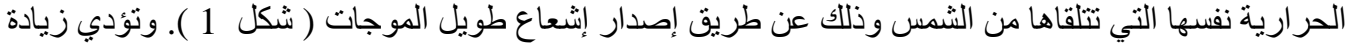

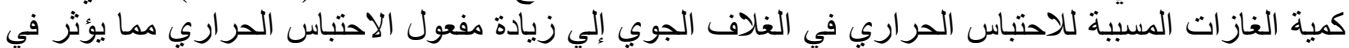

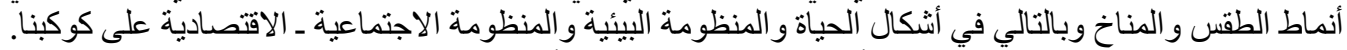

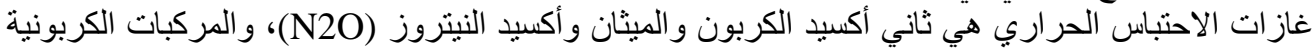

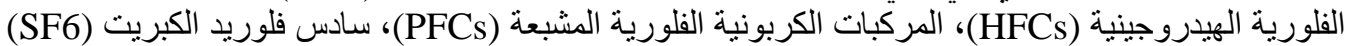

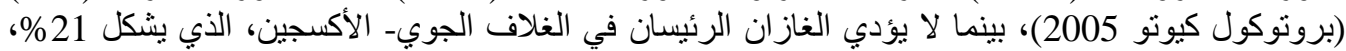

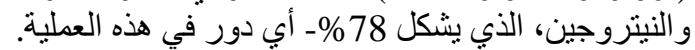

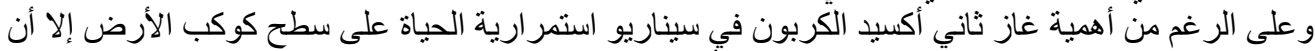

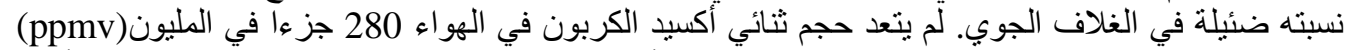

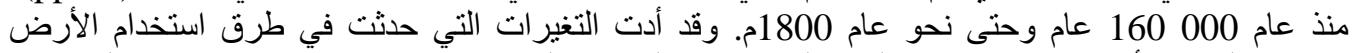

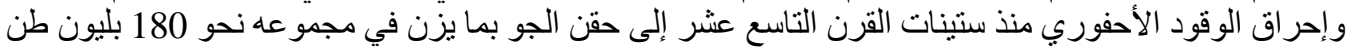
من ثنائي أكسيد الكربون فازد الإدواد محتواه إلي أكثر من 31 \%

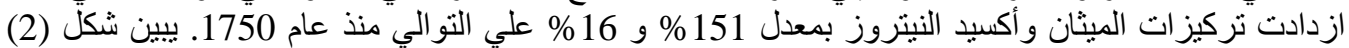

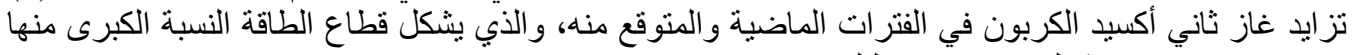
(64,5 \% كما يبين شكل (3) (سفيان التل 2009).

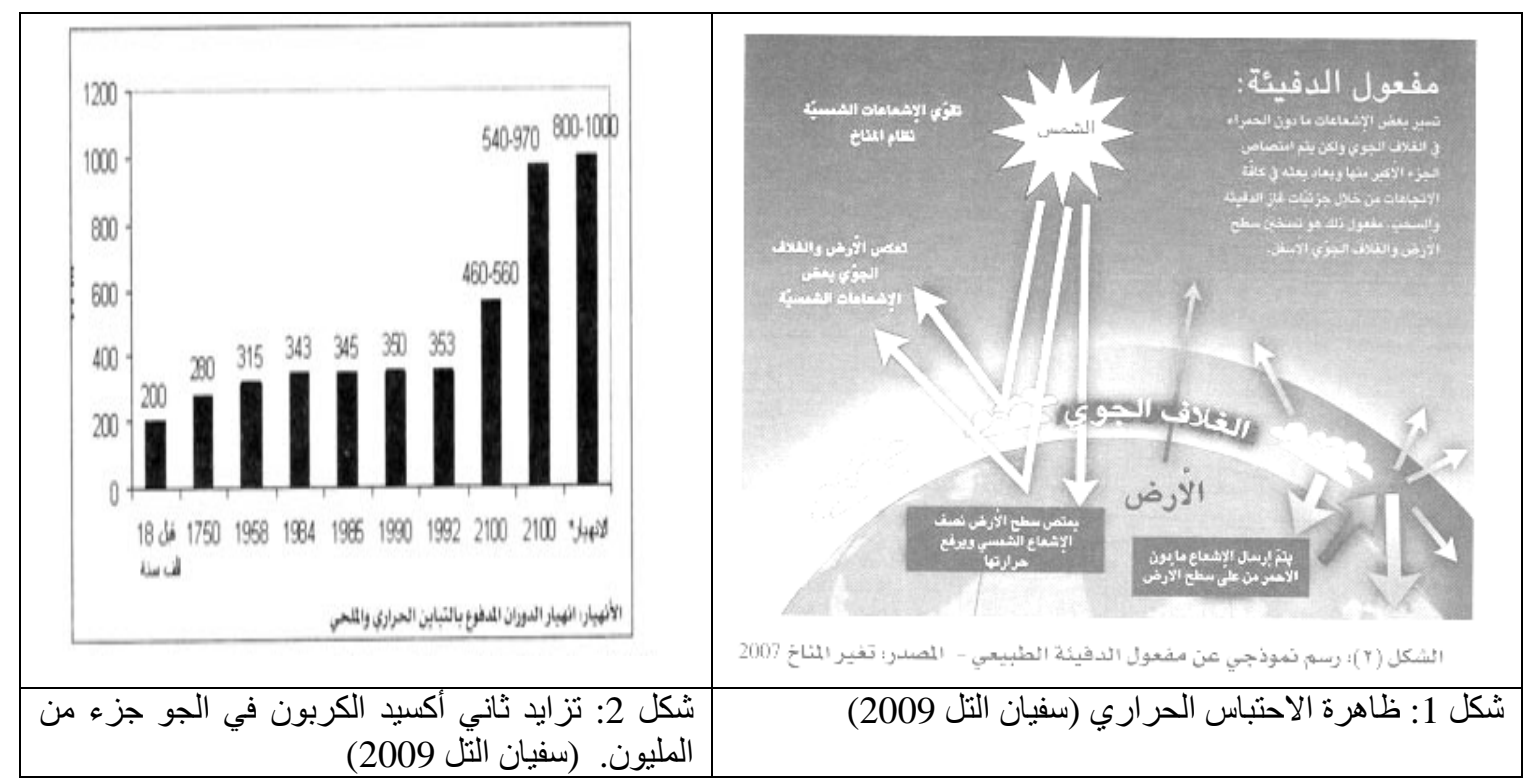




\section{Global Anthropogenic GHG Emissions by Sector 2005}

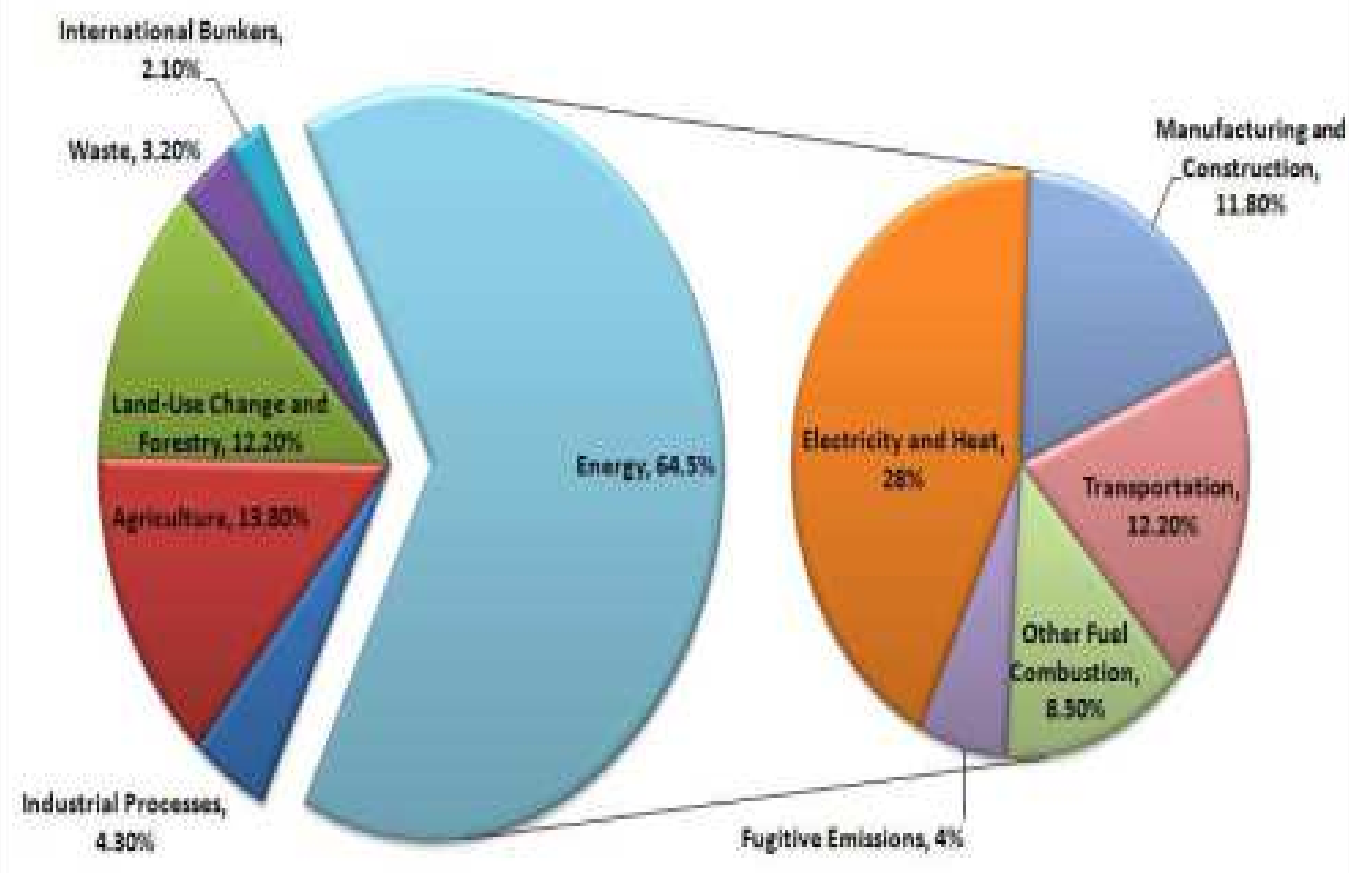

شكل 3: نسبة مشاركة القطاعات المختلفة في انبعانات غاز ات الاحتباس الحراري

(Source: Center for climate and energy solutions) http://www.c2es.org/facts-figures/internationalemissions/sector

يسبب ثاني أكسيد الكربون نحو 50\% من ارتفاع درجات الحرارة نتيجة الاحتباس الحراري كما يبين شكل (4)

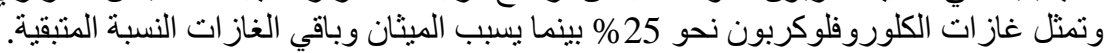

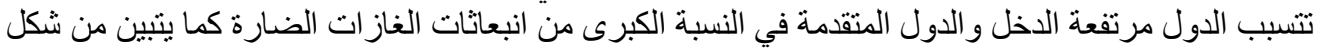

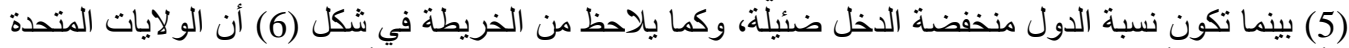

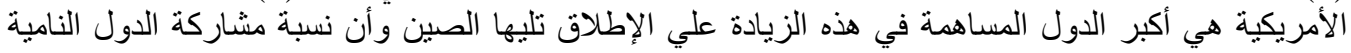

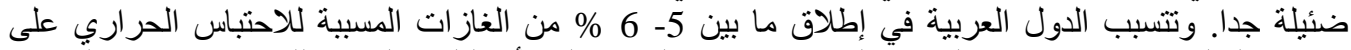

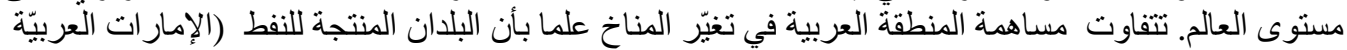

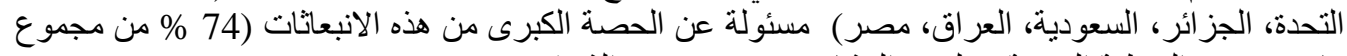
ما ينبعث من المنطقة العربية) (بلقيس العشا، الترد، 2010)، (محمد الثرقي 2010). 


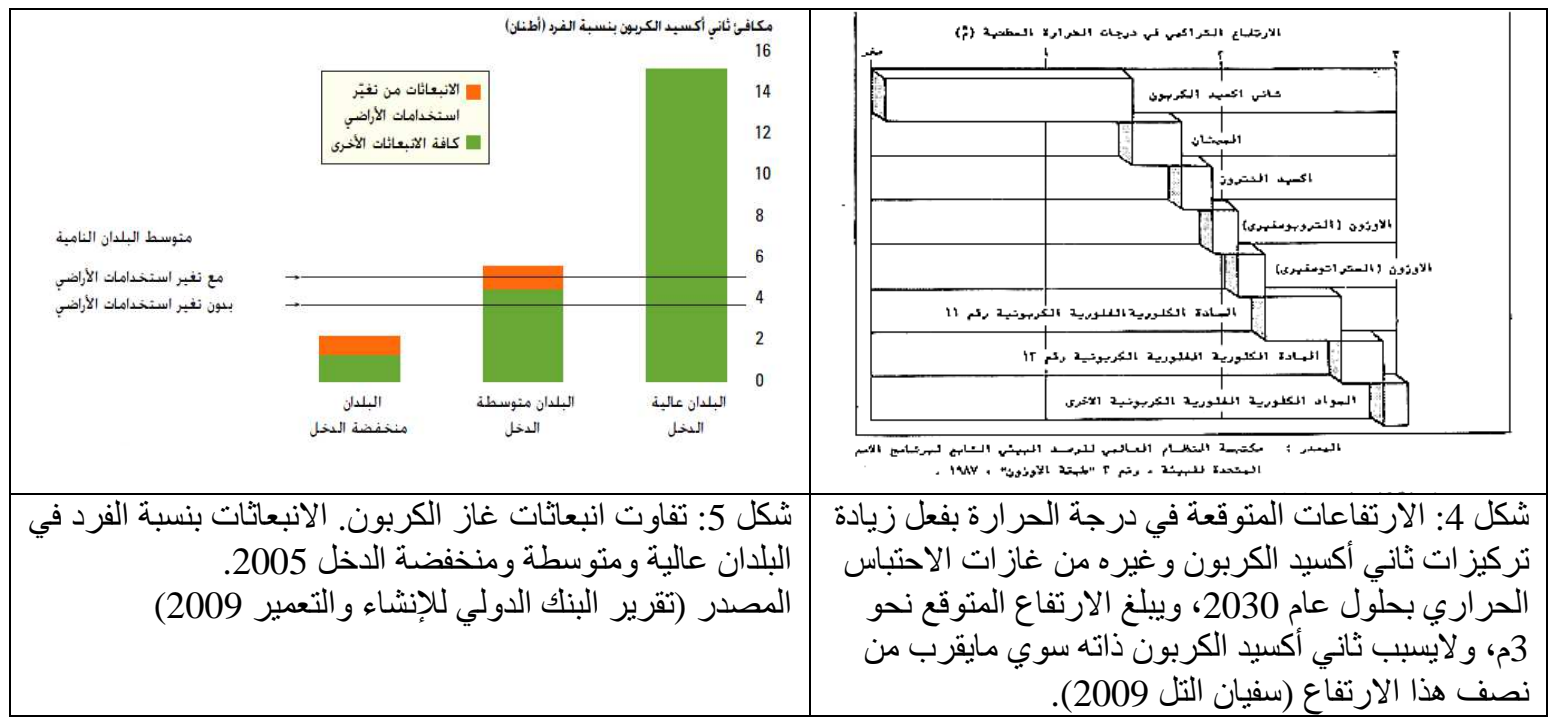

\section{Total $\mathrm{CO}_{2}$ Greenhouse Gas Emissions in the Year 2000, by Country}

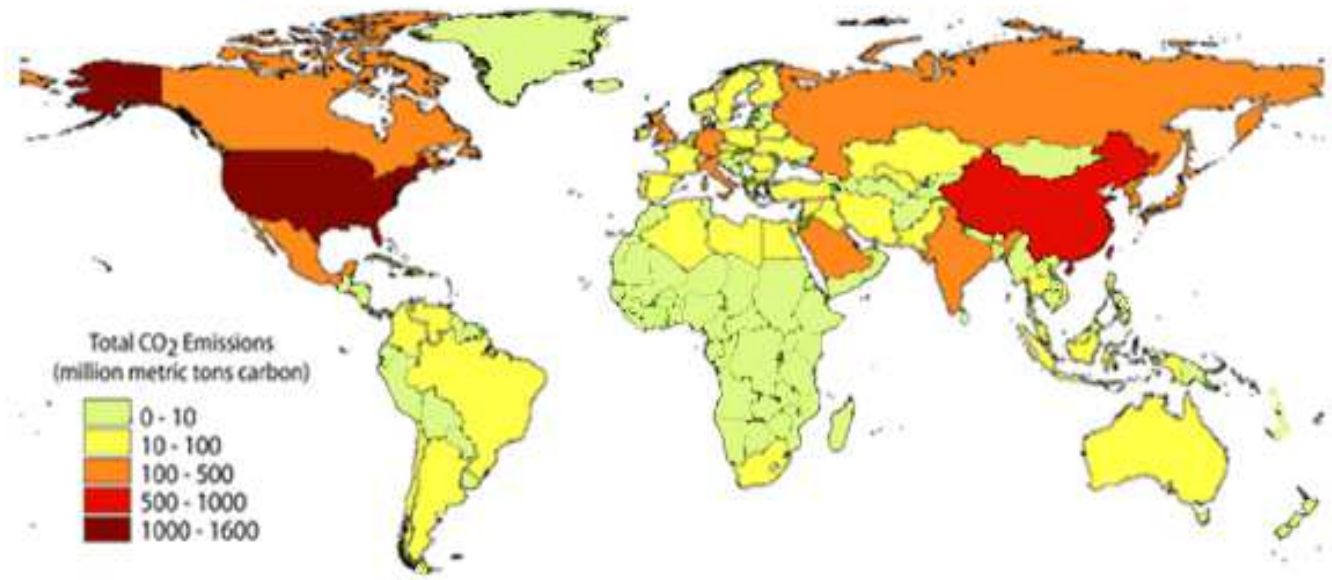

شكل (6): الدول المشاركة في زيادة انبعانات غاز ات الدفيئة ونسب مشاركتها (Paroma Basu, 2005)

\section{3- 3 آثاره علي العالم}

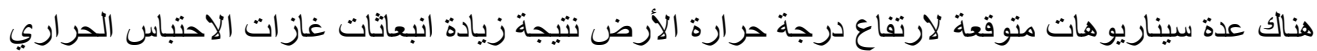

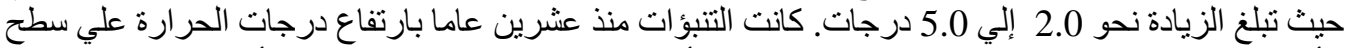

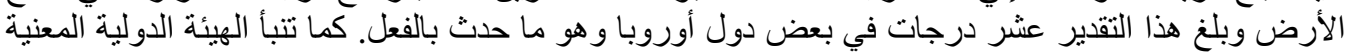

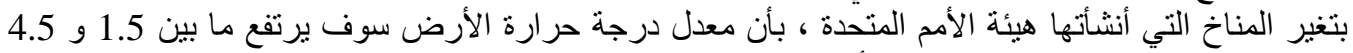

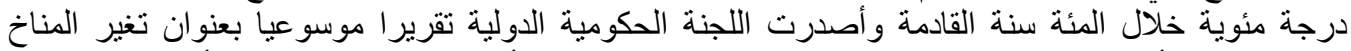

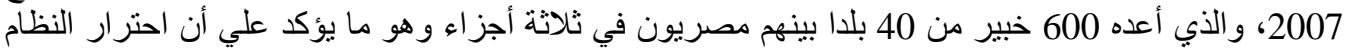

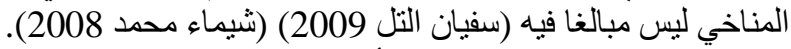

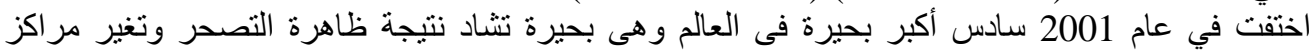

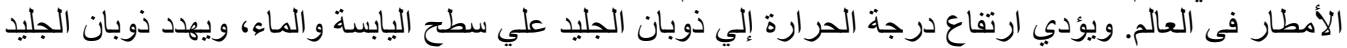

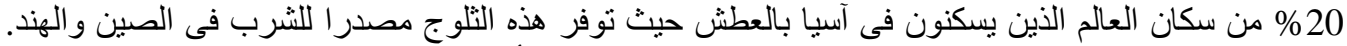
ستؤدي عملية ذوبان الجليد إلي تشريد 40 \% من سكان العالم خلال الأعوام القادمة (فاروق الباز 2007)، 
(شيماء محمد 2008)، كما سيضر ارتفاع درجة حرارة الأرض بالأحياء المالية والطحالب ويؤثر على

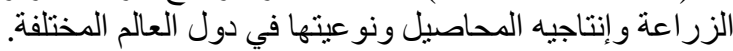

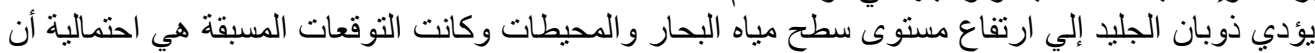

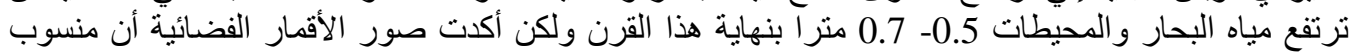

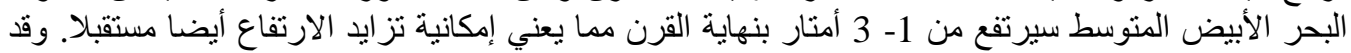

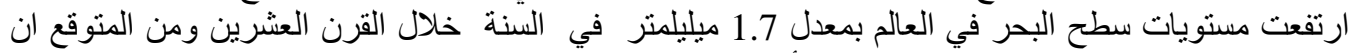

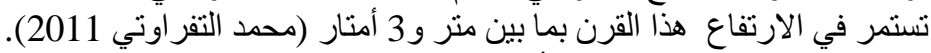

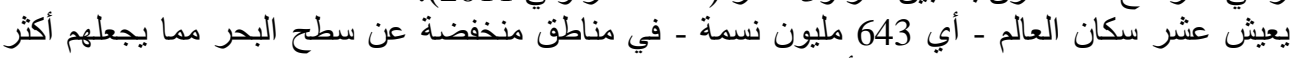

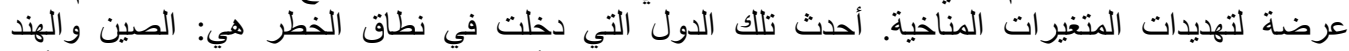

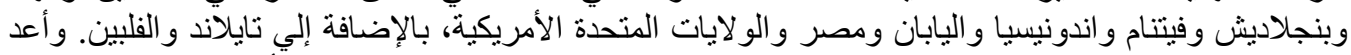

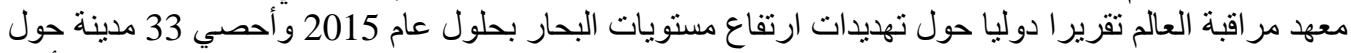

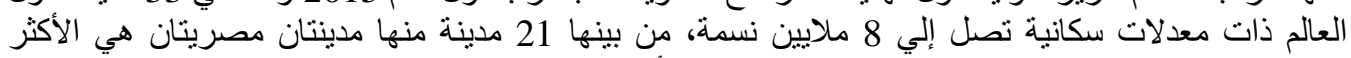

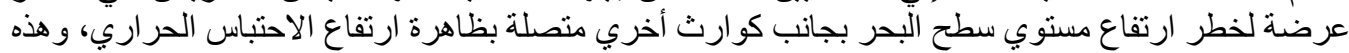

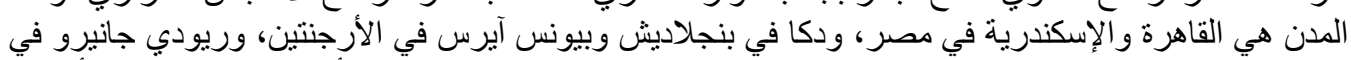

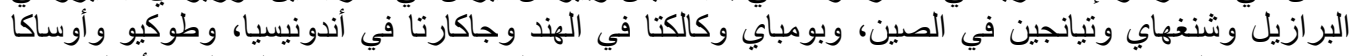

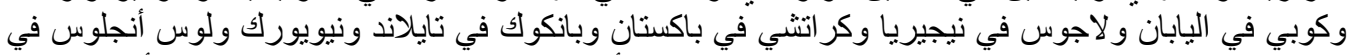

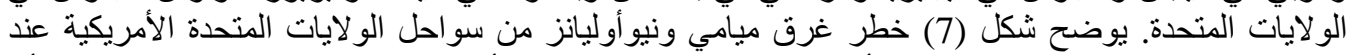

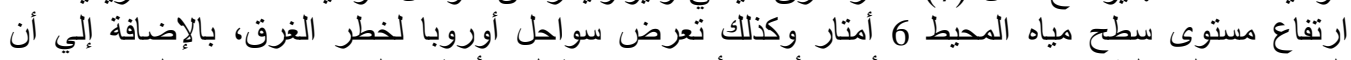

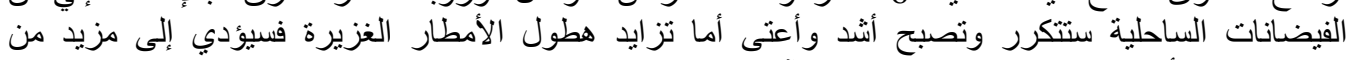

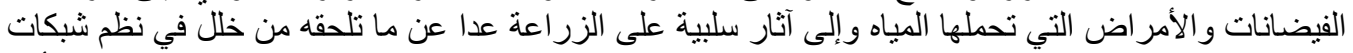

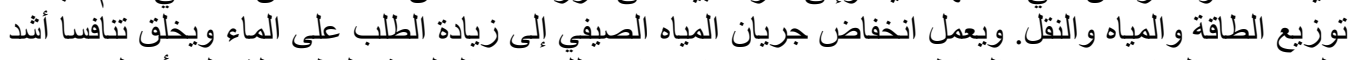

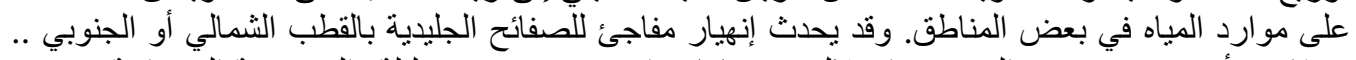
وبدلا من أن يرتفع منسوب البحر منر الخلال 30 عاما .. قد يحدث بين يوم وليلة (الموسوعة الجغر افية 2009)

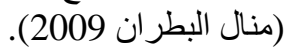

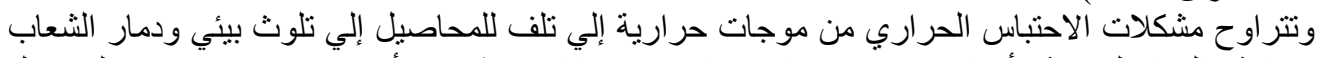

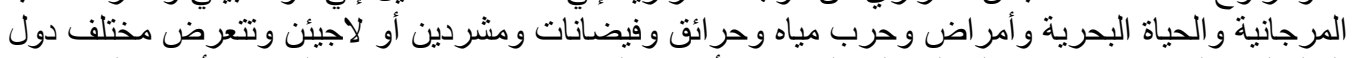

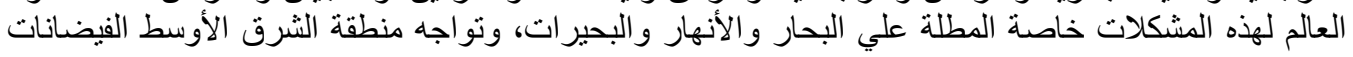

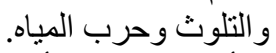

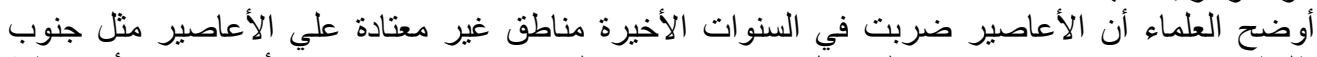

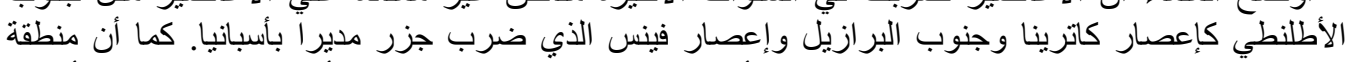

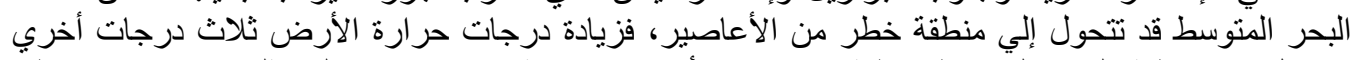

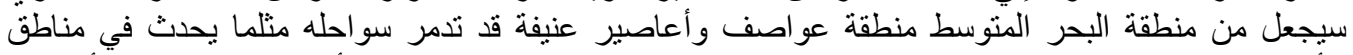

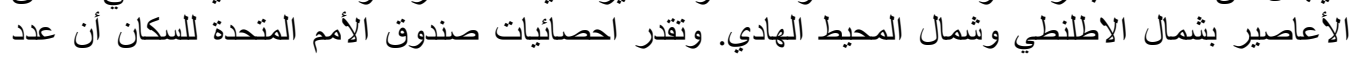

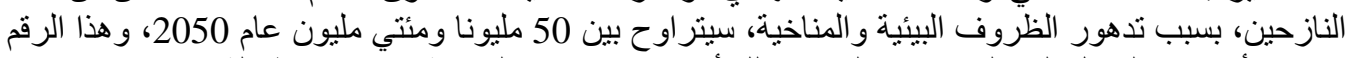

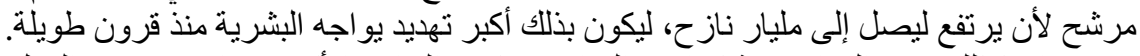

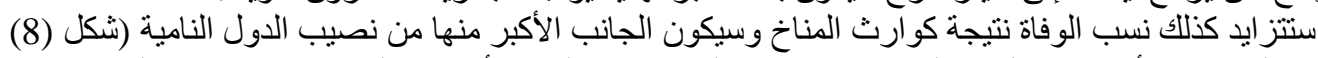

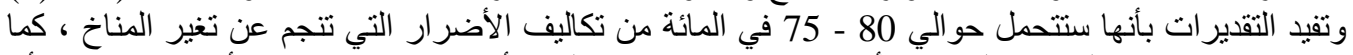

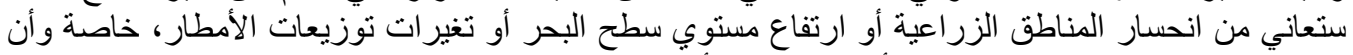

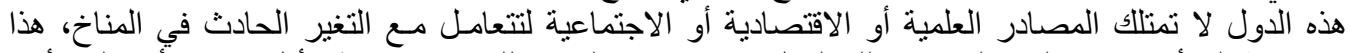

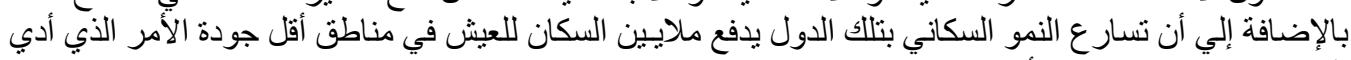
إلي تغير في استخدامات الأراضي. 


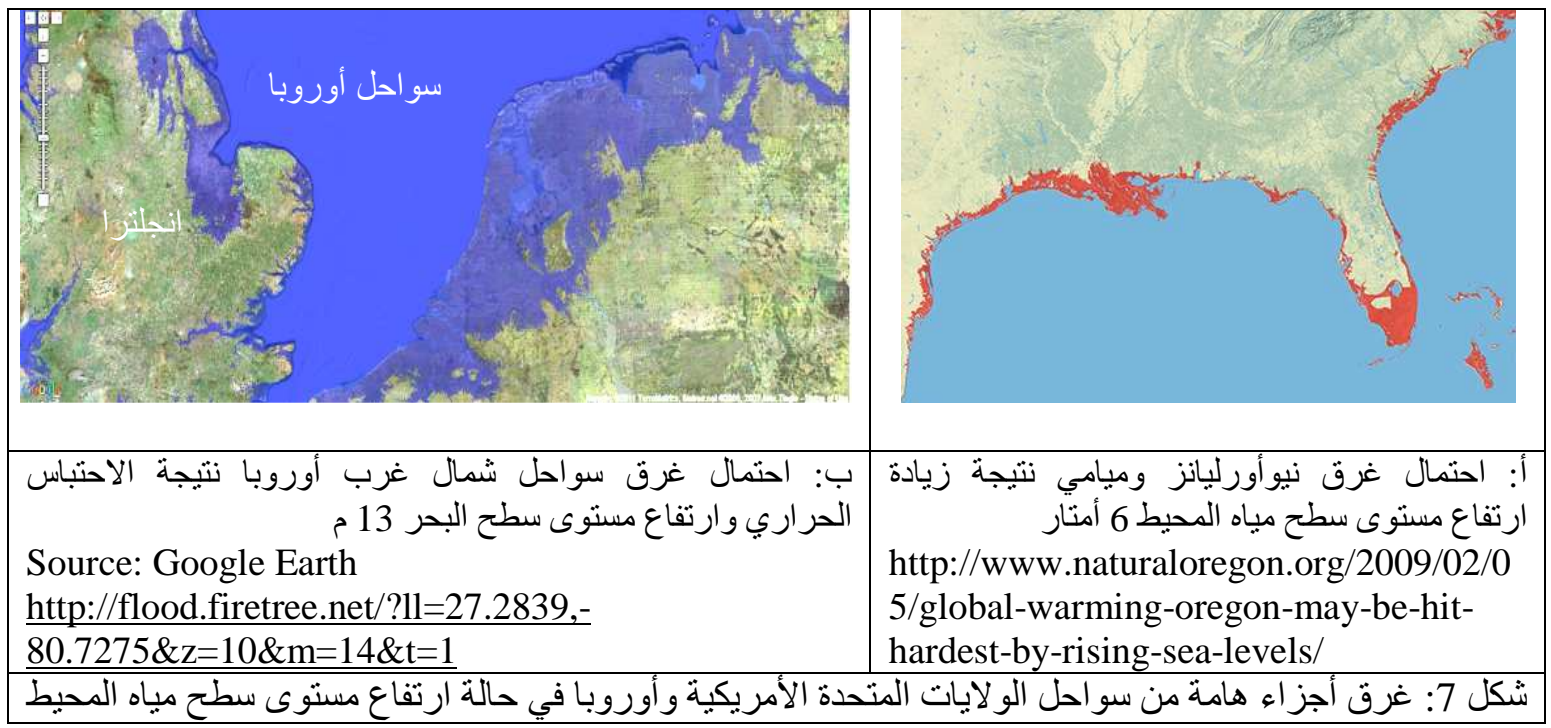

\section{Estimated Deaths Attributed to Climate Change in the Year 2000, by Subregion*}

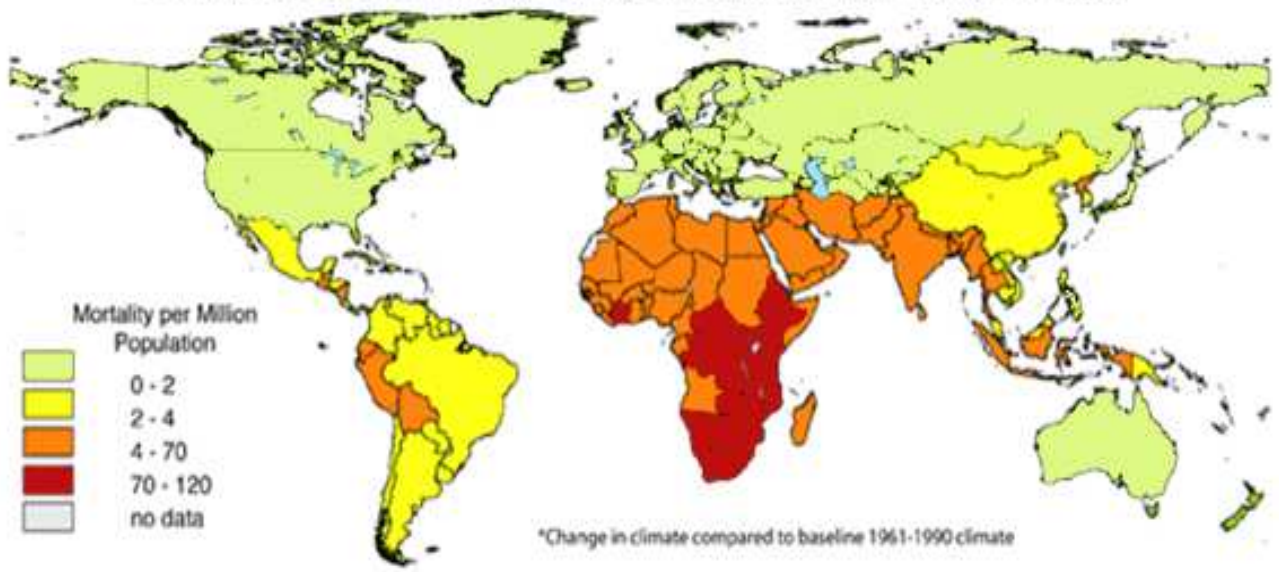

شكل 8 : نسب الوفاة المتوقعة في العالم نتيجة الاحتباس الحراري (Paroma Basu, 2005)

يوضح شكل (9) وشكل (10) مشكلات ومخاطر الاحتباس الحراري علي العالم. وقد بلغت خسائر كو ارث التغير التغير

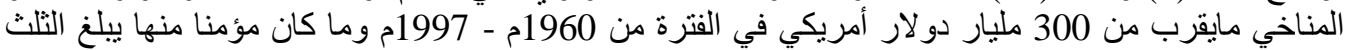

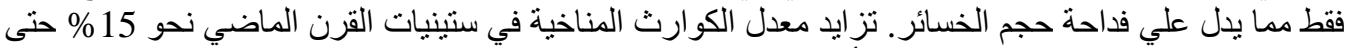

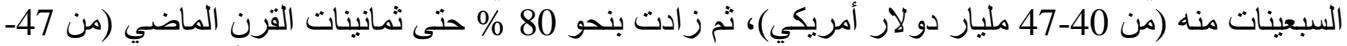

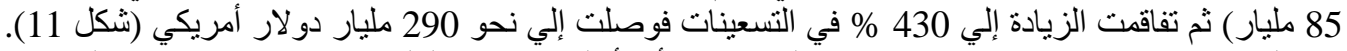

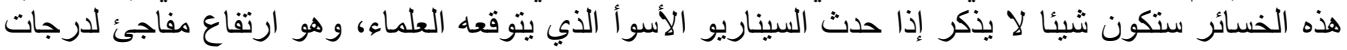

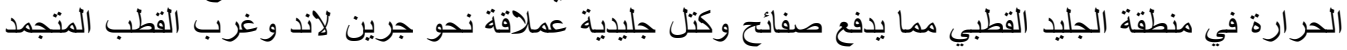




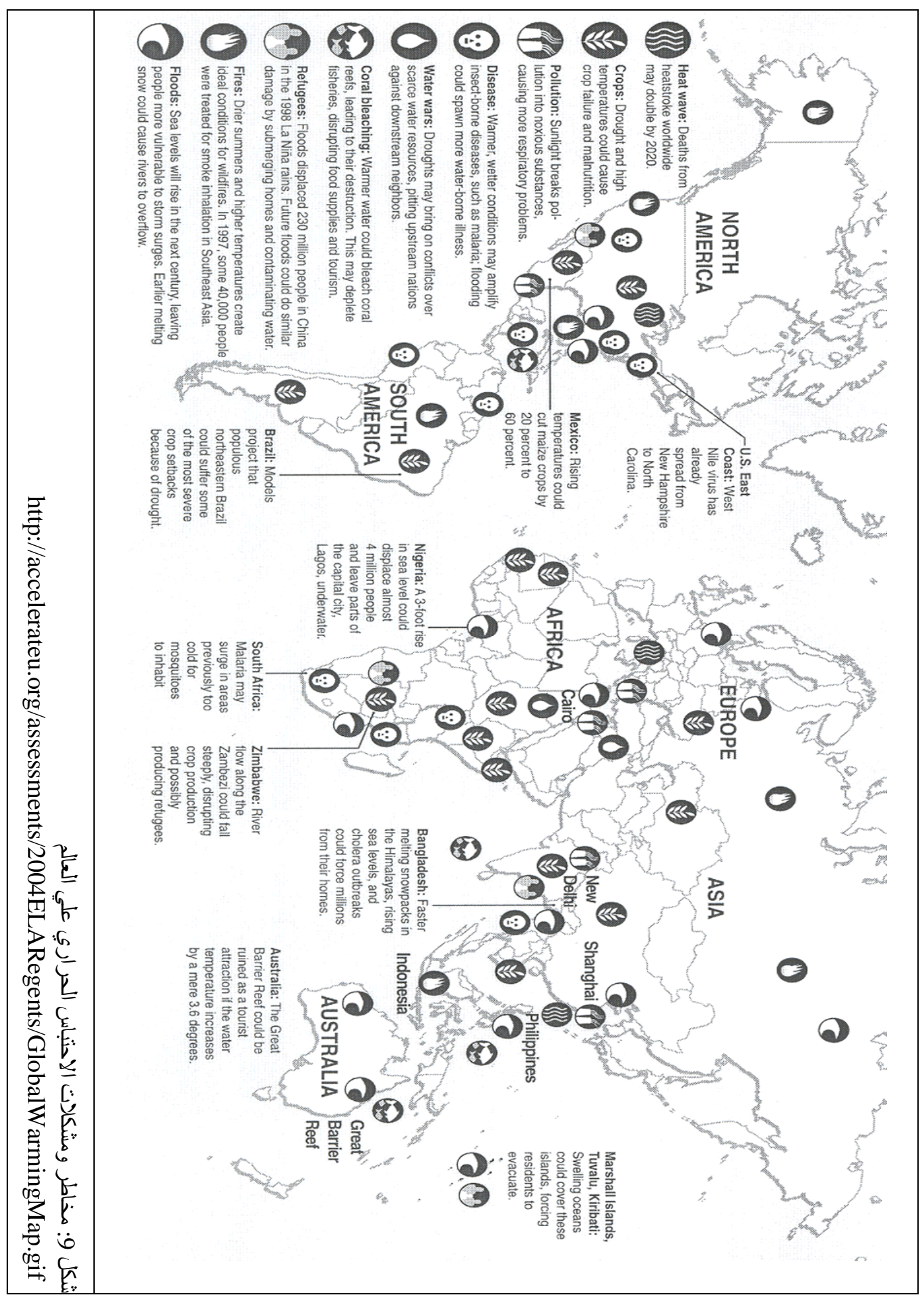




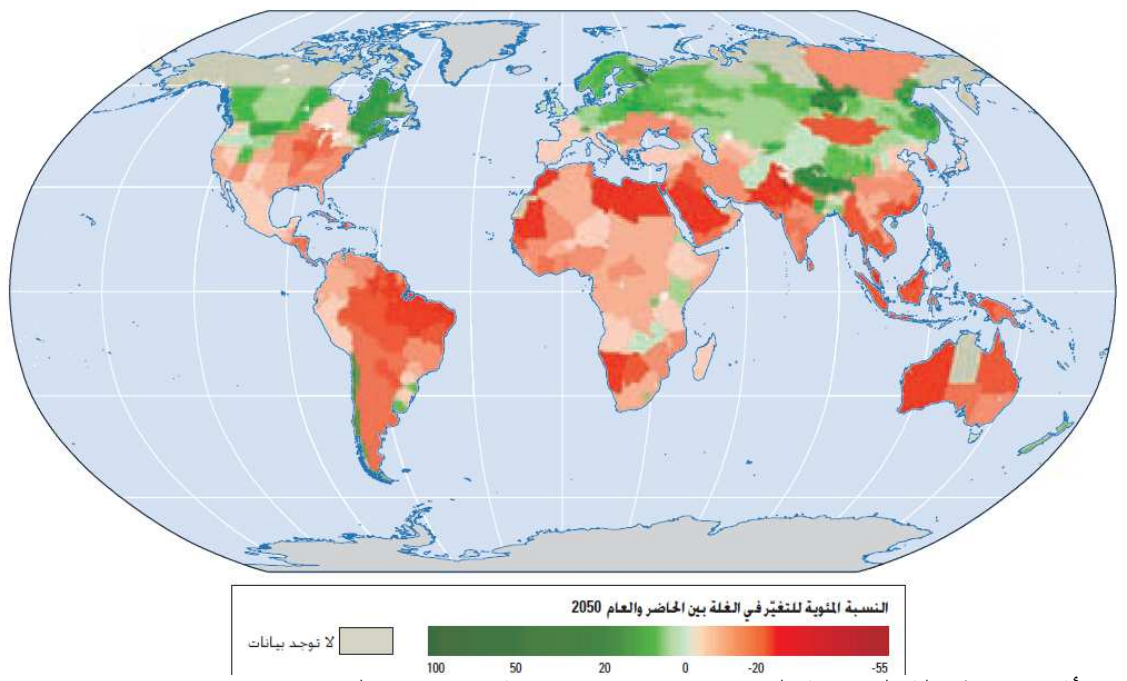

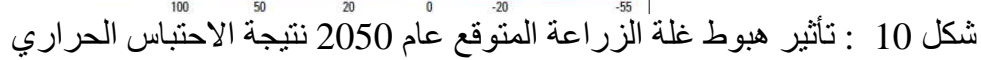

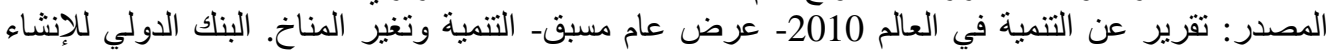
و التعمير 2009.

أما المشكلة الكبري فهي تباطؤ دوران التيار الناقل في شمال الأطلسي وهو مايحدث نتيجة امتصاص المياه لغاز

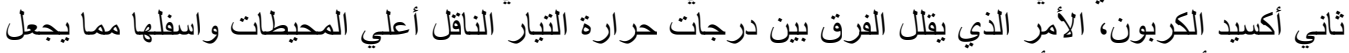

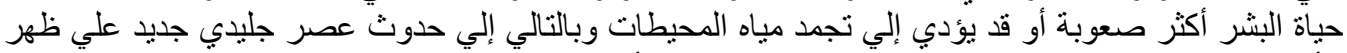

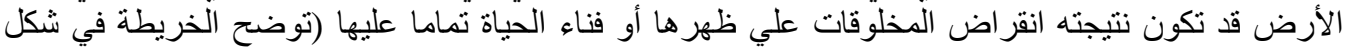

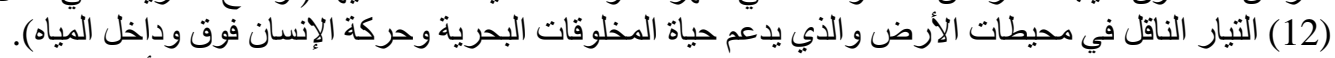

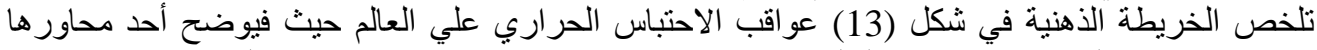

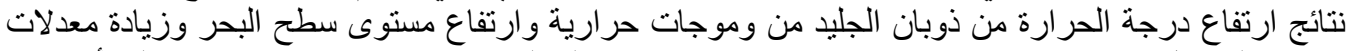

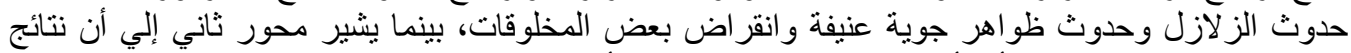

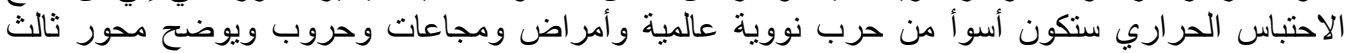

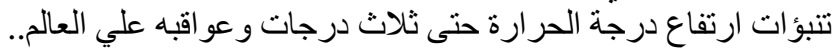

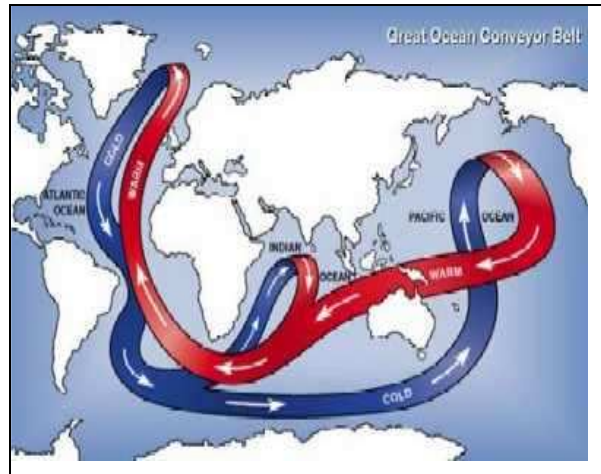

شكل 12: التيار الناقل في محيطات الأرض (The Great Ocean Conveyer Belt, 2000)

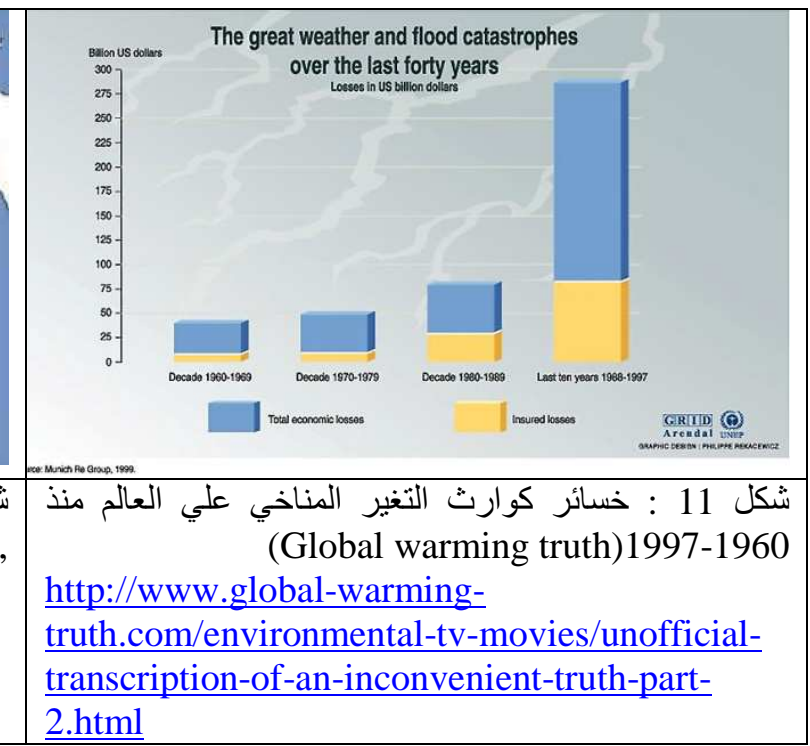




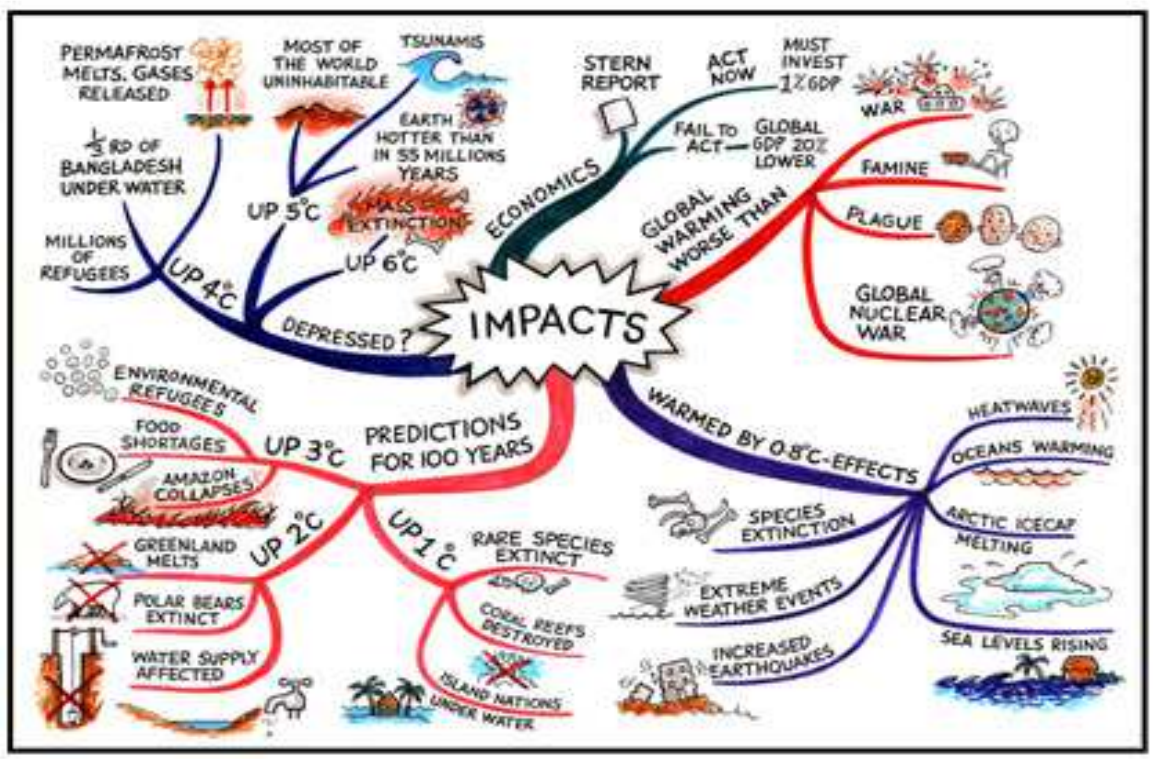

شكل 13: عو اقب وتبعات الاحتباس الحراري علي العالم

Source: http://live-the-solution.com/wp-content/uploads/impacts-mindmap.jpg

\section{4- آثاره علي المنطقة العربية:}

تبعا لتقرير شركة ميونيخ ري العالمية لإعادة التأمين ستكون المنطقة العربية وشرق آسيا الأكثر تأثر ا بين أقاليم

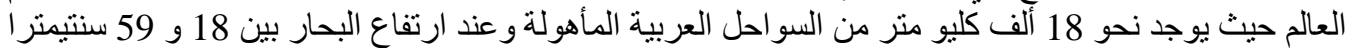

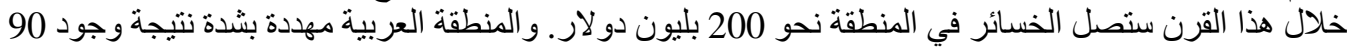

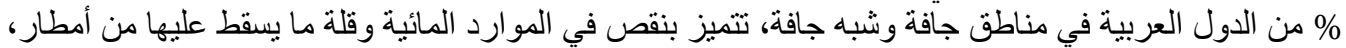

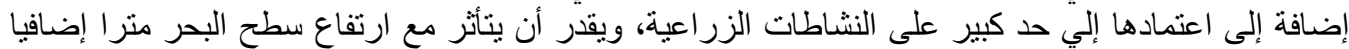

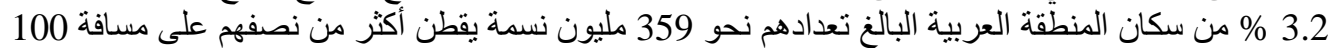

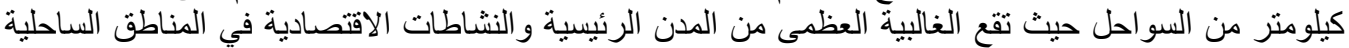

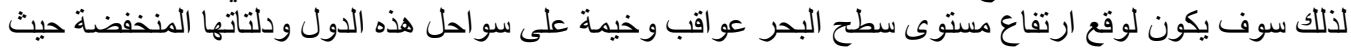

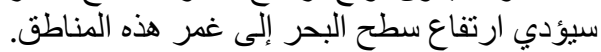

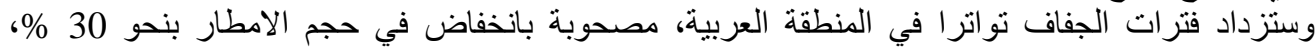

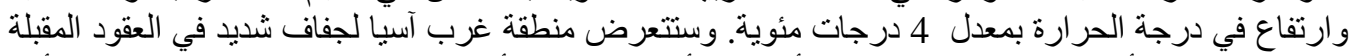

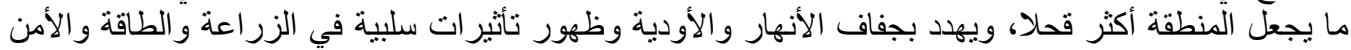

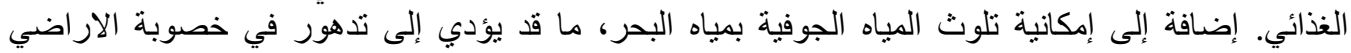

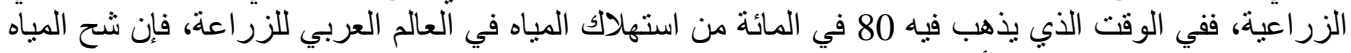

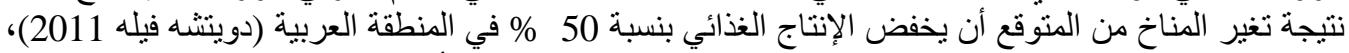

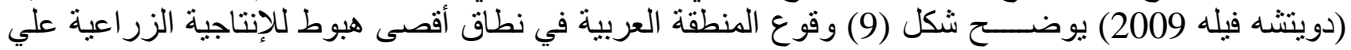

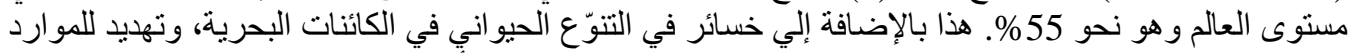

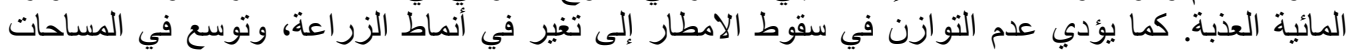

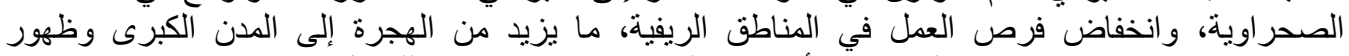

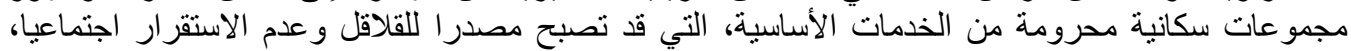

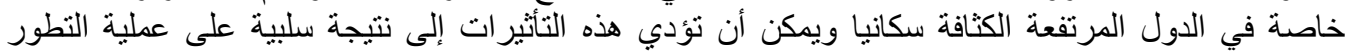

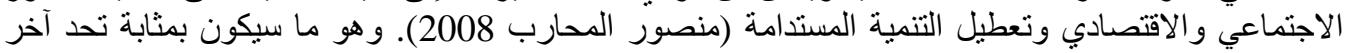

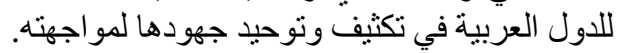


وفي منطقة الجزيرة العربية والخليج العربي ستغرق أراضي ساحلية نتيجة ارتفاع مستوى مباه البحار

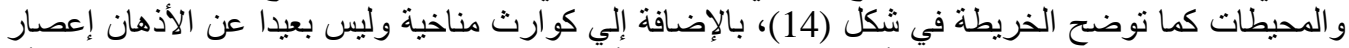

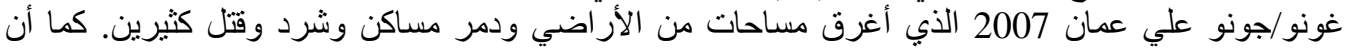

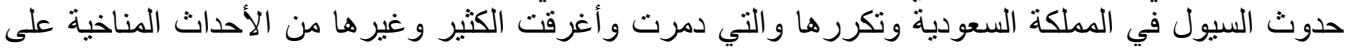

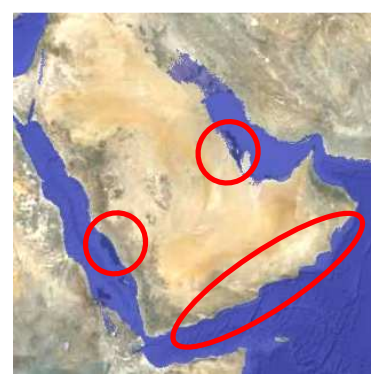

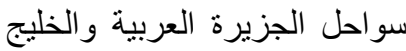
العربي عند ارتفاع مستوى سطح الجئح

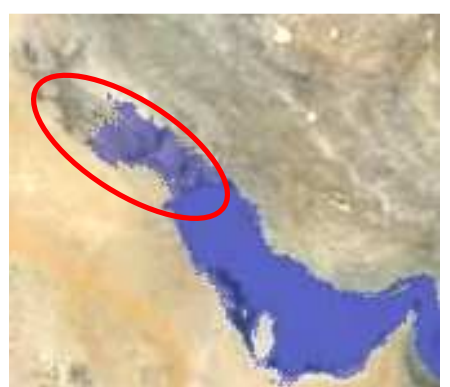

منطقة قمة الخليج عند ارتفاع مياة الخليج 13 منرا

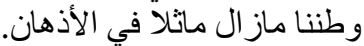

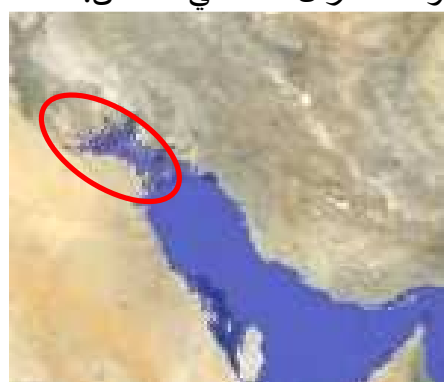

منطقة قمة الخليج عند ارتفاع مياة

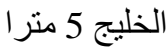

المياه المحيطة 13 مثرا المنار

شكل 15: غرق سواحل بالجزيرة العربية و الخليج العربي عند ارتفاع مستوى سطح المياه المحيطة 5 أمتار و 13 متر

Source: Google Earth http://flood.firetree.net/?11=27.2839,-80.7275\&z=10\&m=14\&t=1

وفي مصر ستغمر مياه البحر المتوسط الهناطق الساحلية. وكما سبق ذكرة فإن هنالك مدينتين مصريتين من بين

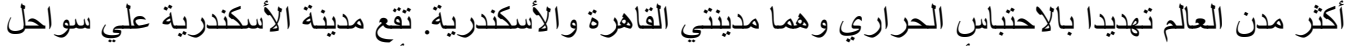

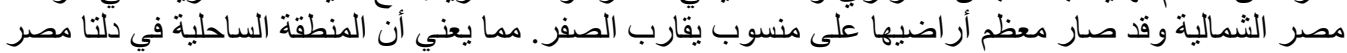

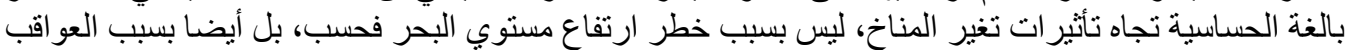

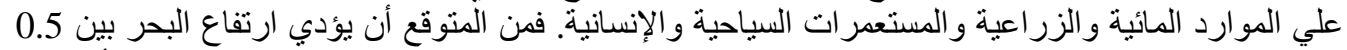

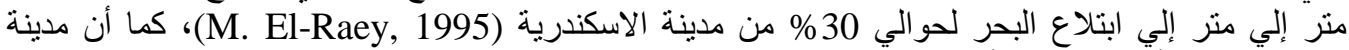
بورسعيد هي الأخري مهددة بأخطار مماتلكة.

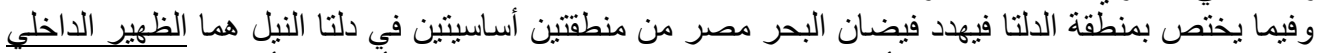

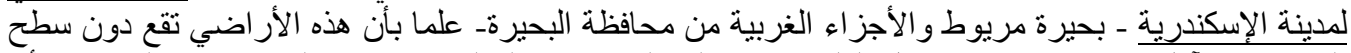

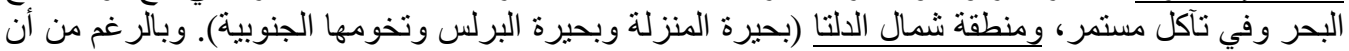

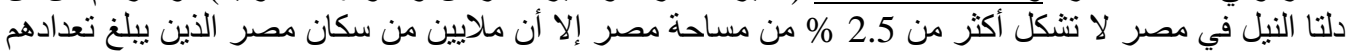

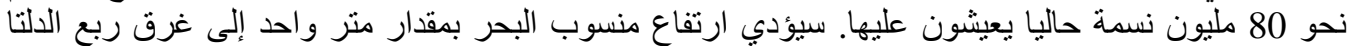

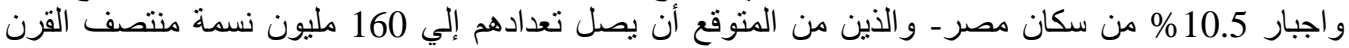

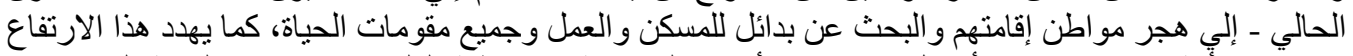

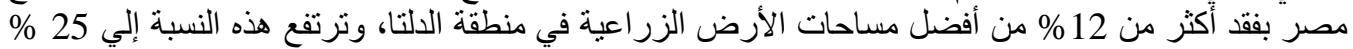

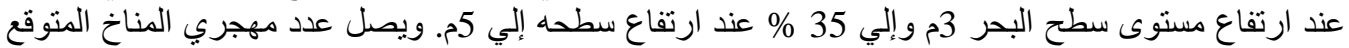

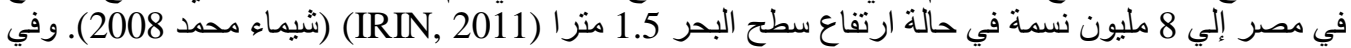

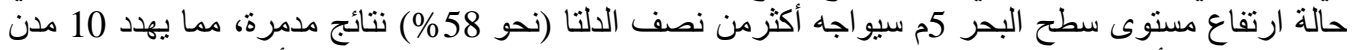

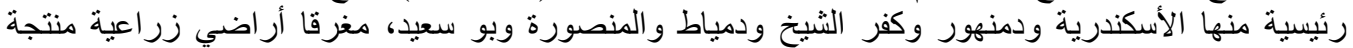

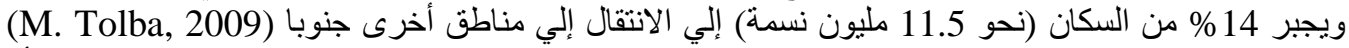

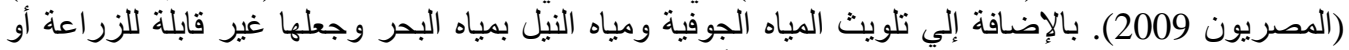

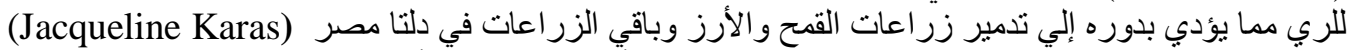

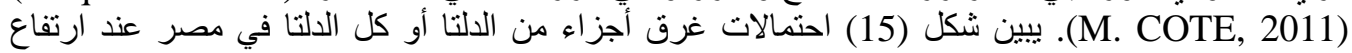
مستوى مياه البحار و المحبطات.

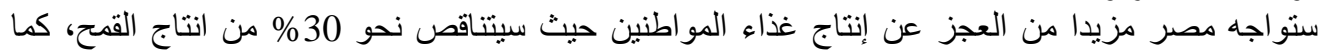

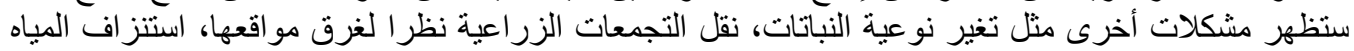




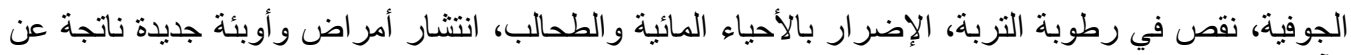

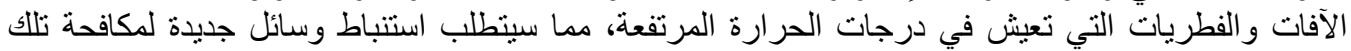

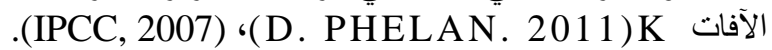
وقد بدأت مصر بالفعل تعاني من نتائج الاحتباس الحراري حيث بدأت ظواهر الهر جوية عنيفا في الحدوث

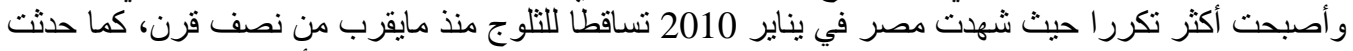

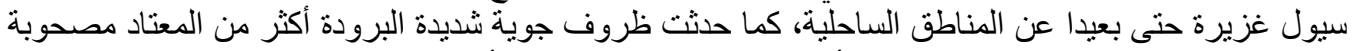

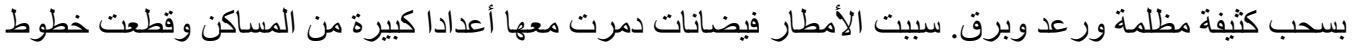

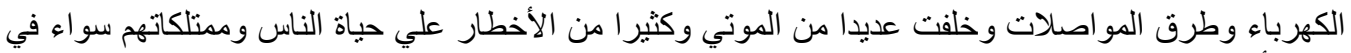

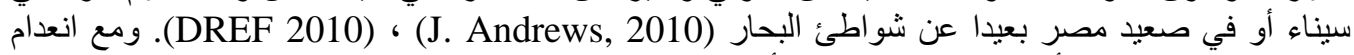

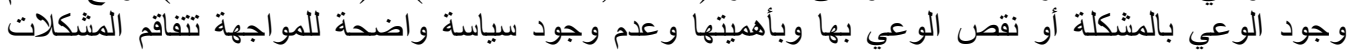
و الآثار المدمرة للاحتباس الحر اري علي مصي المعر و المنطقة العربية.
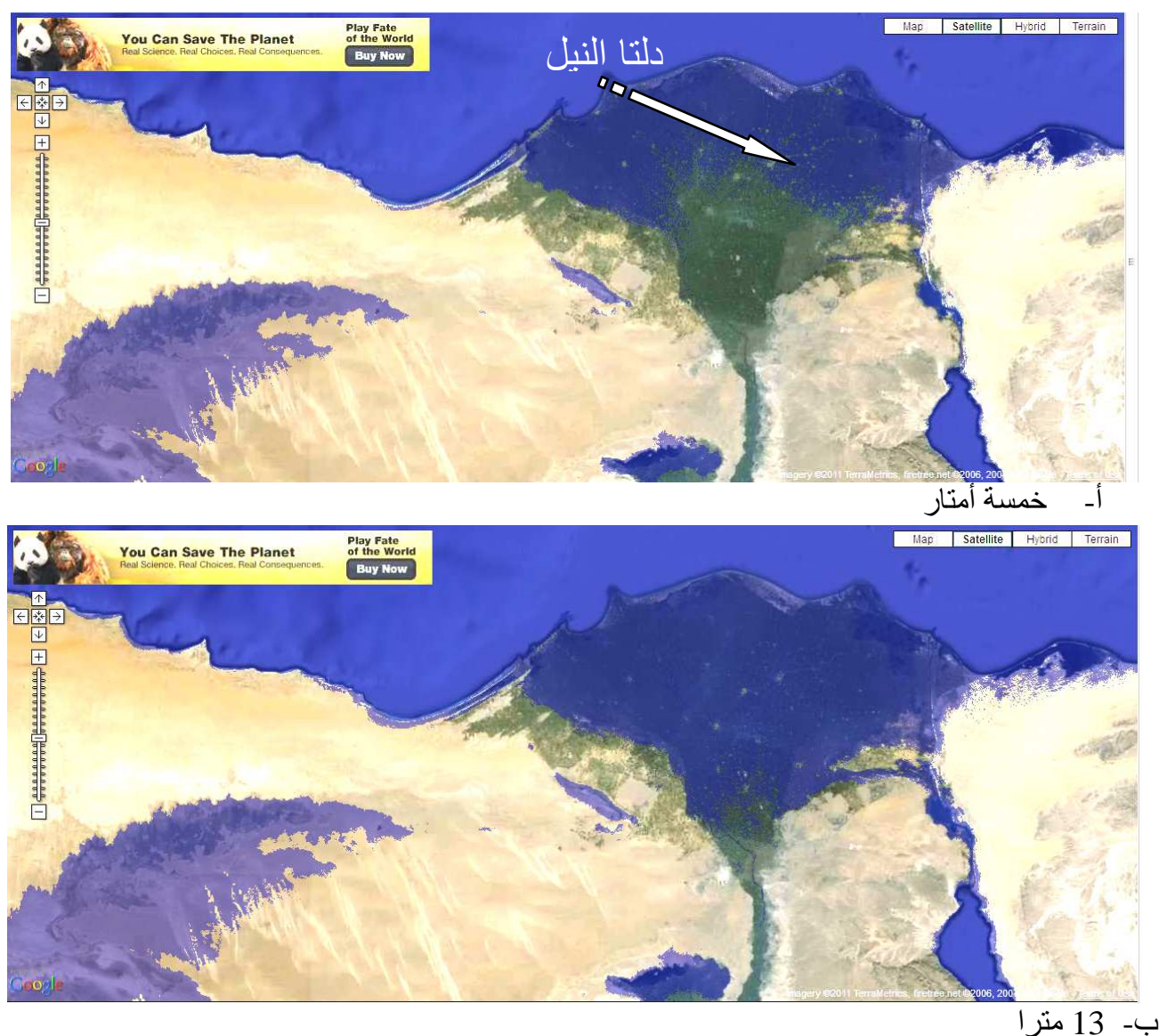

شكل 16: غرق دلتا النيل في مصر نتيجة ارتفاع مسنوى سطح مياه البحر المنوسط كنتيجة للاحتباس الحرار اي : لناي Source: Google Earth http://flood.firetree.net/?1l=27.2839,-$\underline{80.7275 \& \mathrm{z}=10 \& \mathrm{~m}=14 \& \mathrm{t}=1}$

\section{5- اتفاقيات وبروتوكولات دولية}

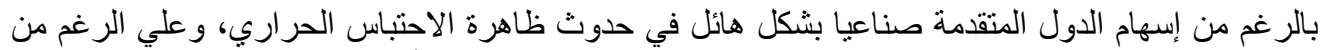

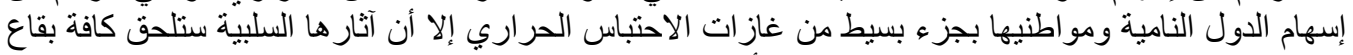

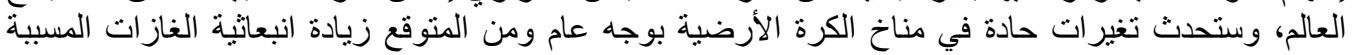


للاحتباس الحراري بنسبة 50\% في الفترة من 2004-2030 في حال عدم وجود اتفاقيات دولية فاعلة لتقليل

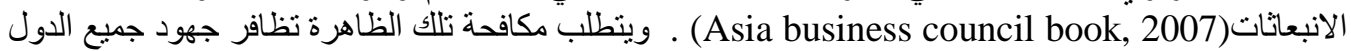

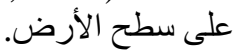

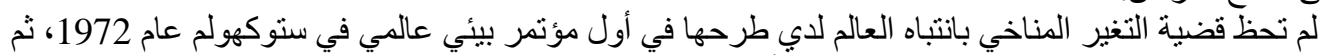

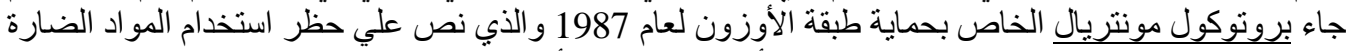

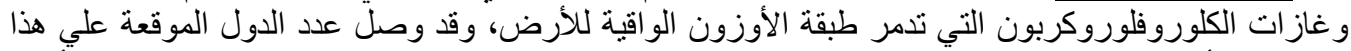

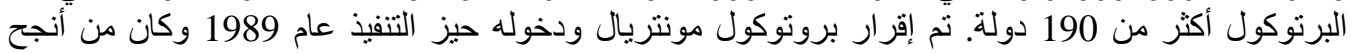

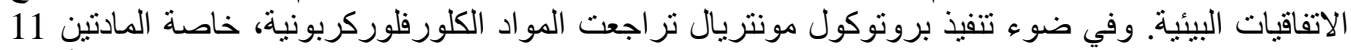

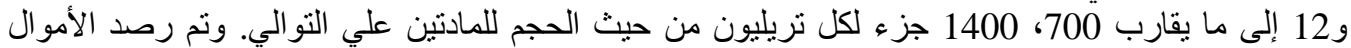

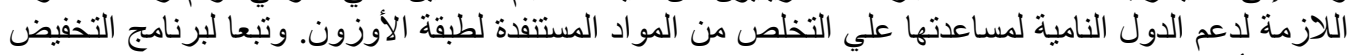

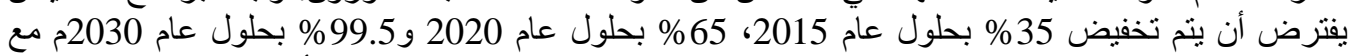
السماح باستعمال 0.5\% في بعض الخدمات حتى عام 2040م.

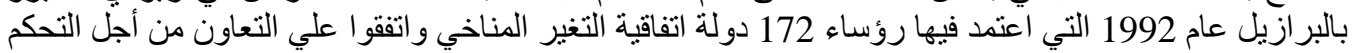

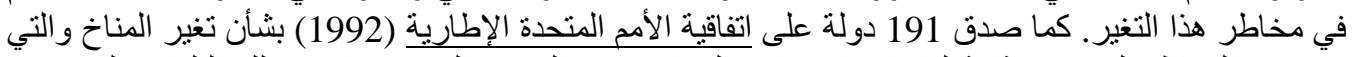

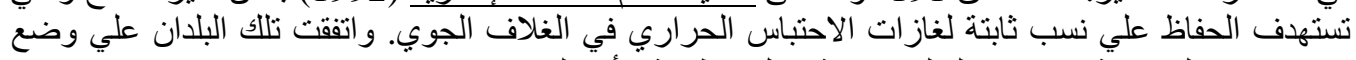

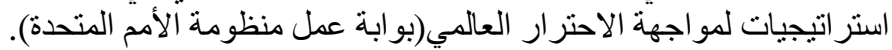

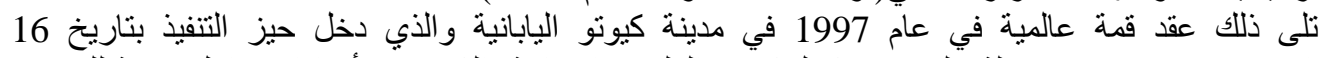

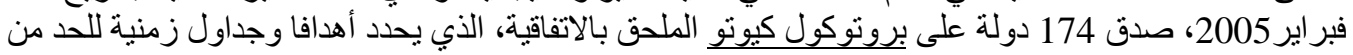

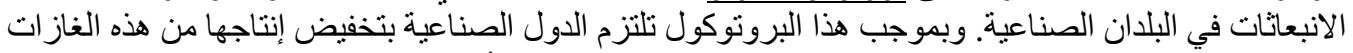

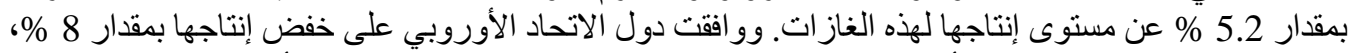

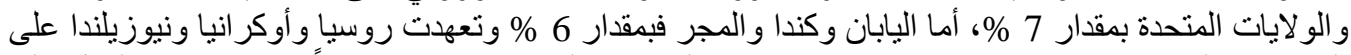

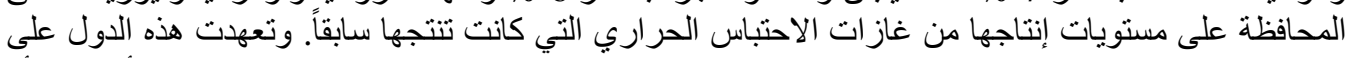

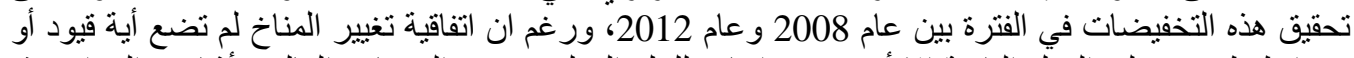

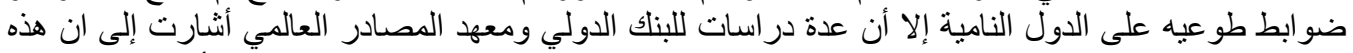

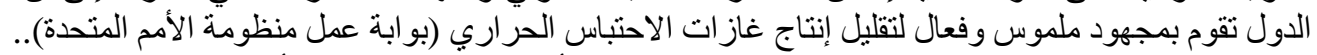

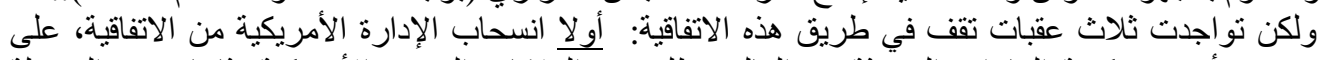

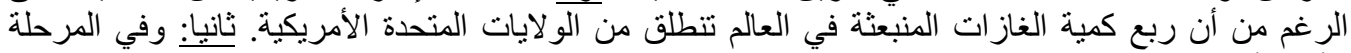

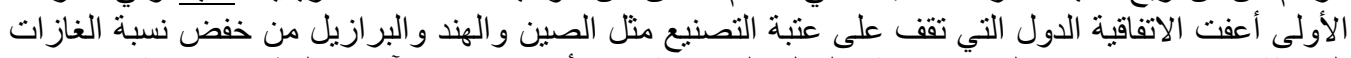

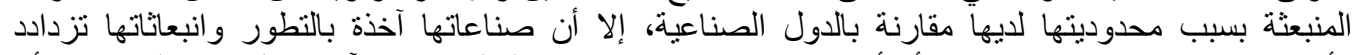

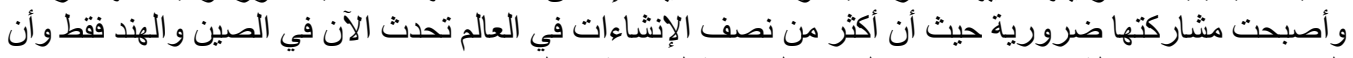

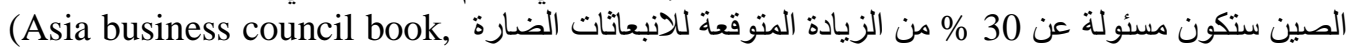

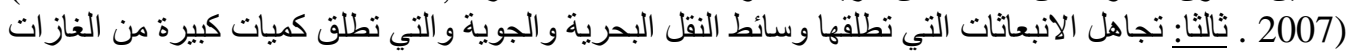

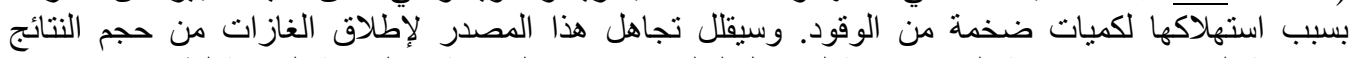

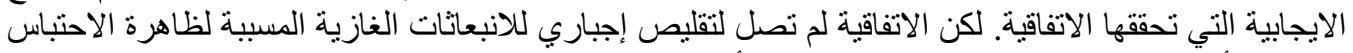

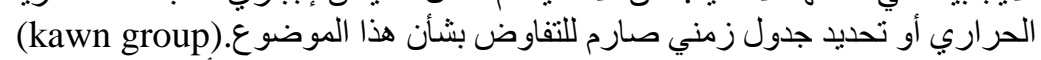

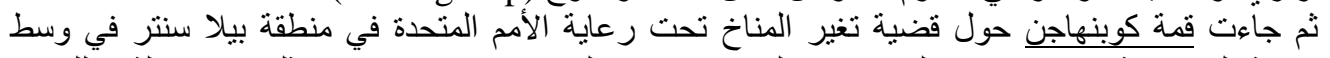

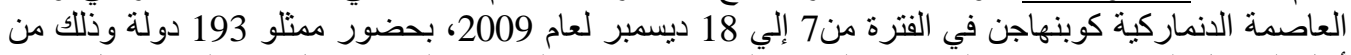

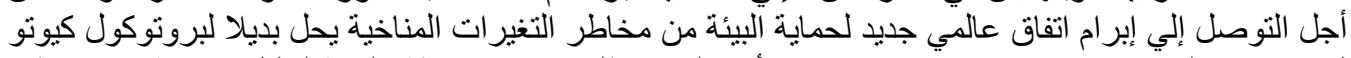

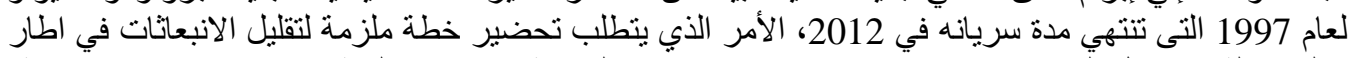

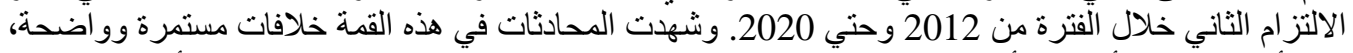

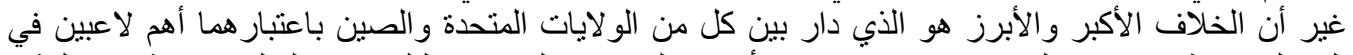

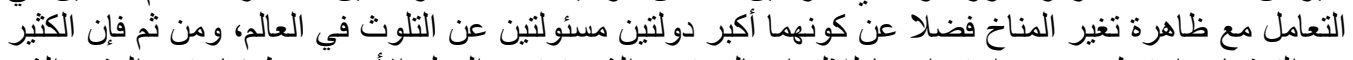

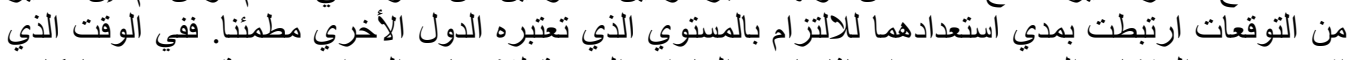

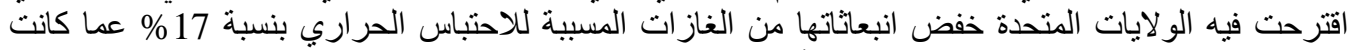

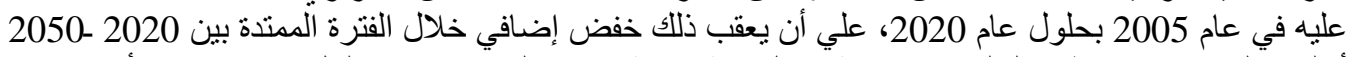

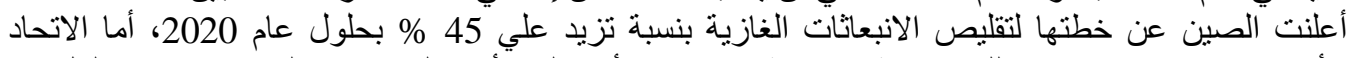

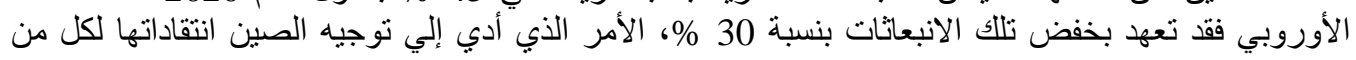




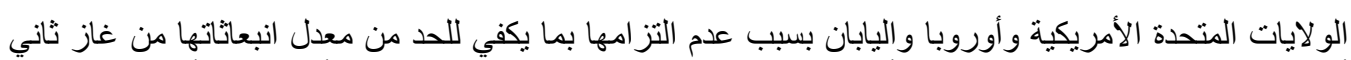

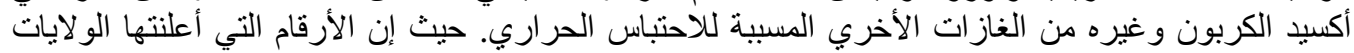

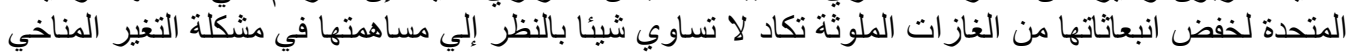

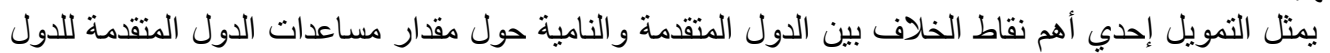

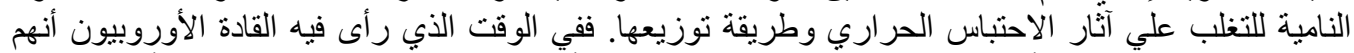

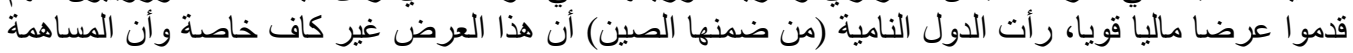

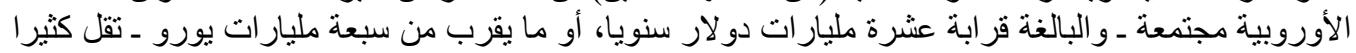

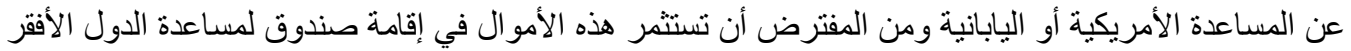

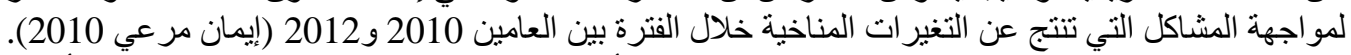

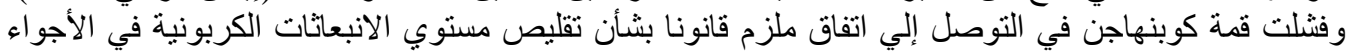

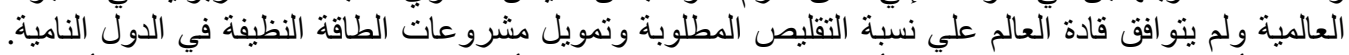

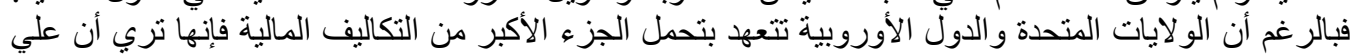

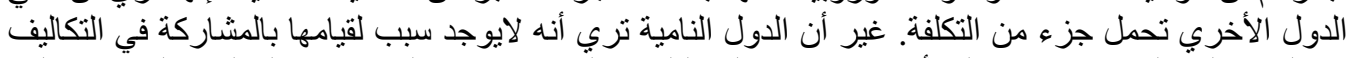

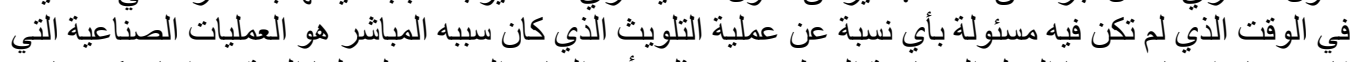

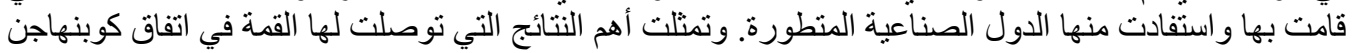

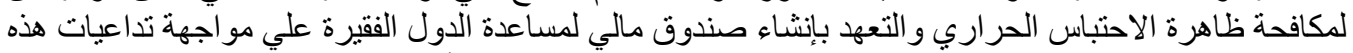

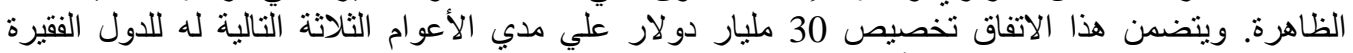

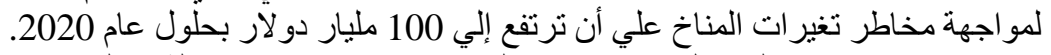

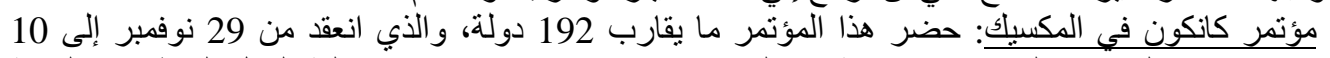

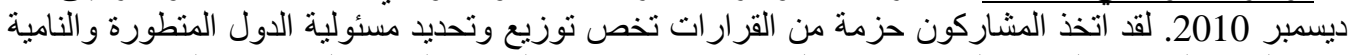

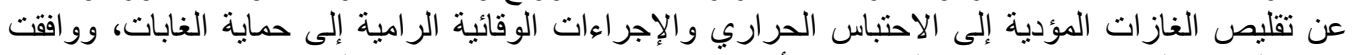

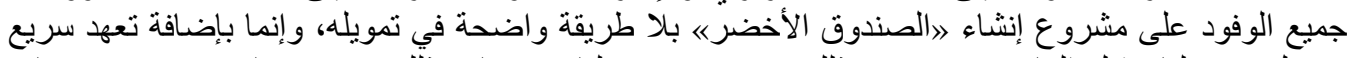

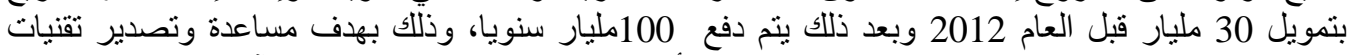

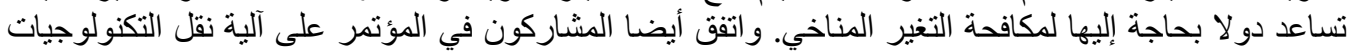

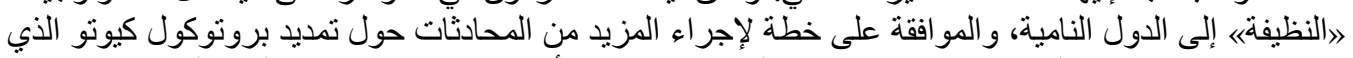

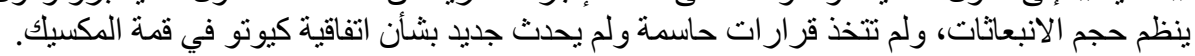

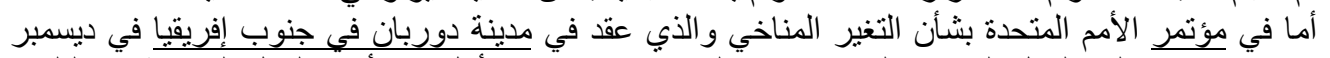

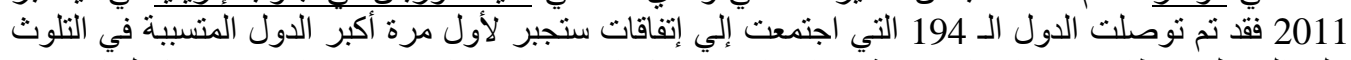

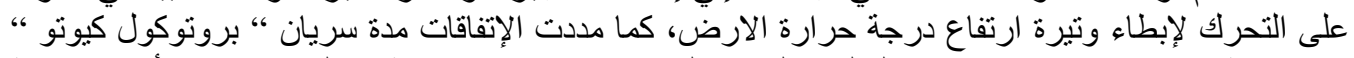

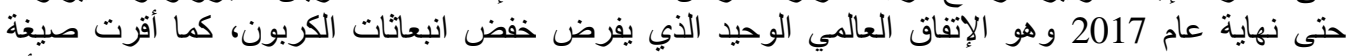

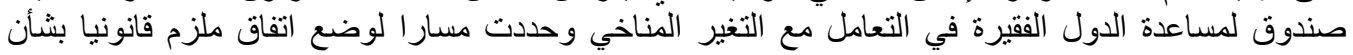

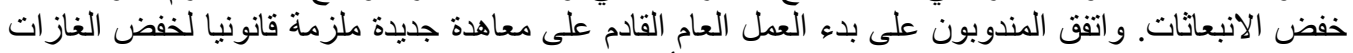

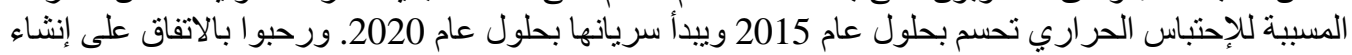

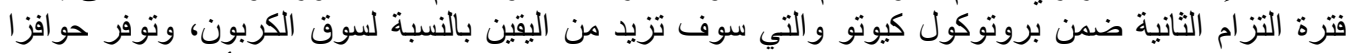

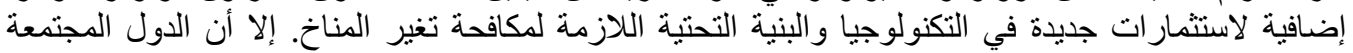

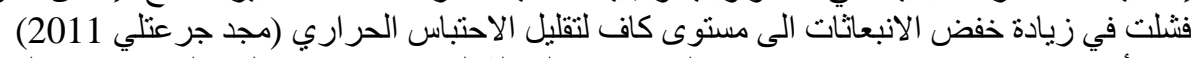

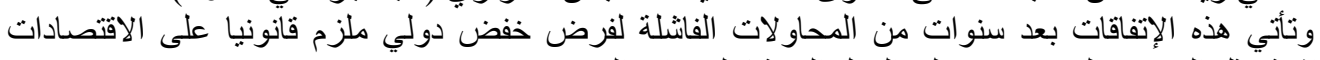

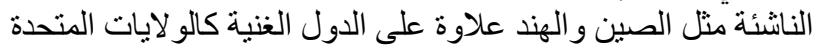

\section{6- مشروعات للحل (عالمية) :}

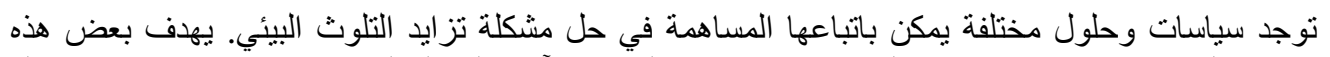

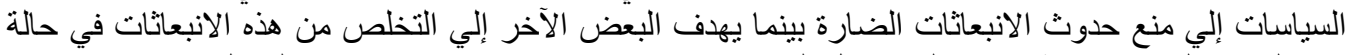

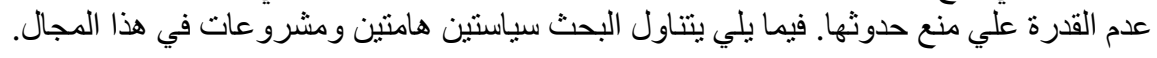


توجد المخازن الطبيعية للكربون في الغلاف الجوي و المحيطات والرسو بيات و الغلاف الحيوي، ويحدث التبادل

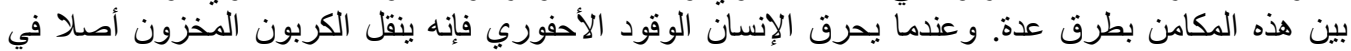

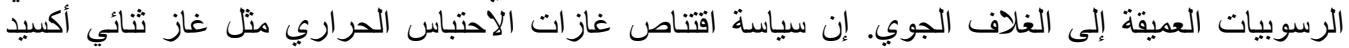

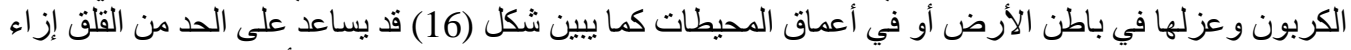

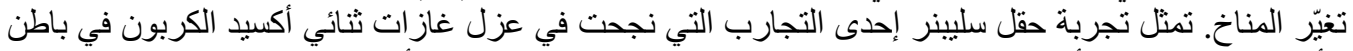

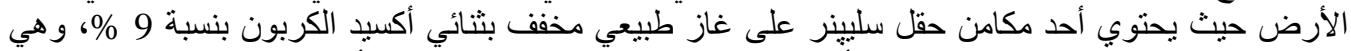

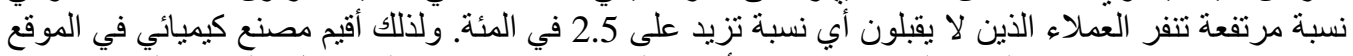

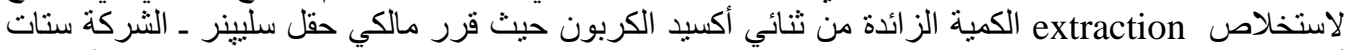

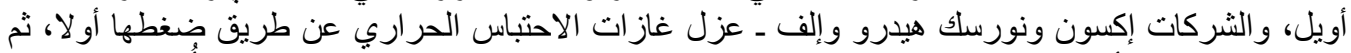

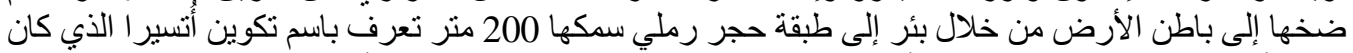

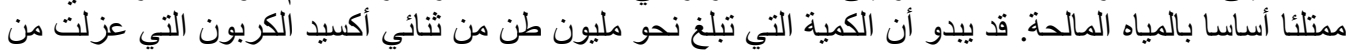

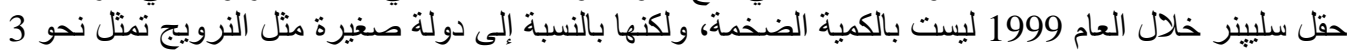

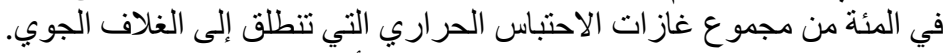

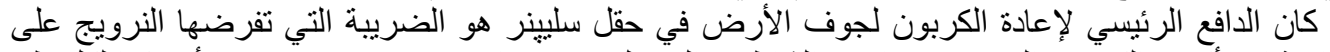

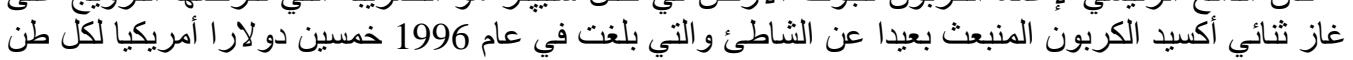

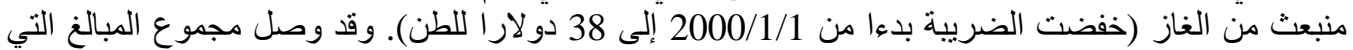

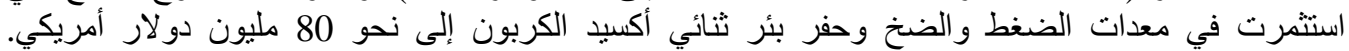

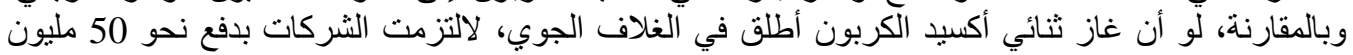

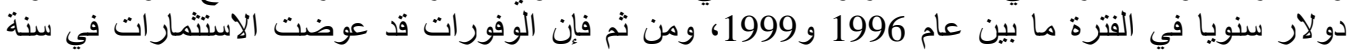

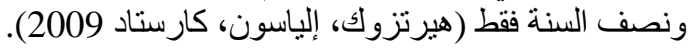

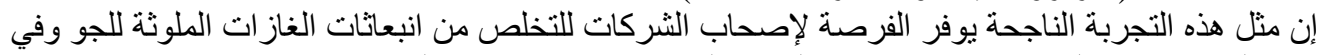

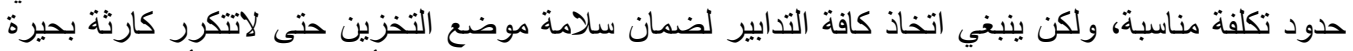

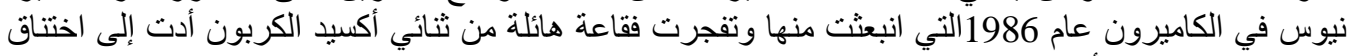
نحو 1700 شخص (أبوكريم 2008).

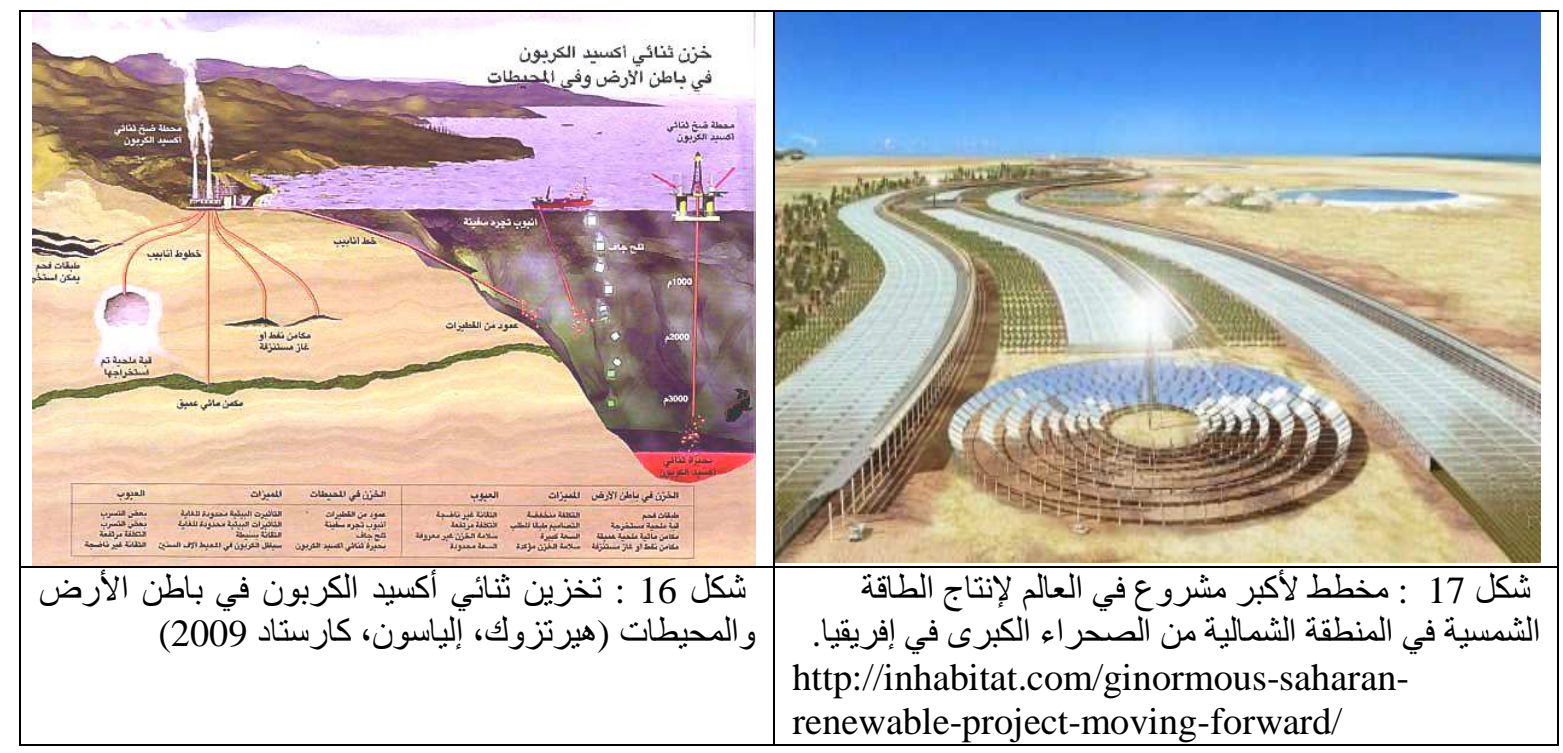


وقد أثبت هذا التوجه جدوى من حيث توفر هذه الطاقات والانخفاض المستمر في التقنيات اللازمة مع تحسن

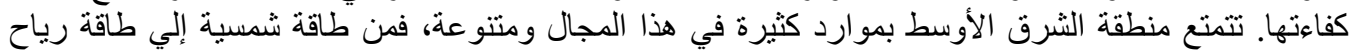

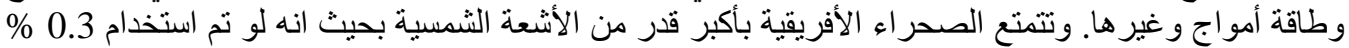

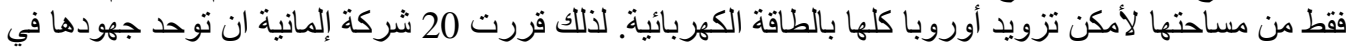

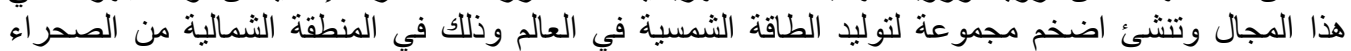

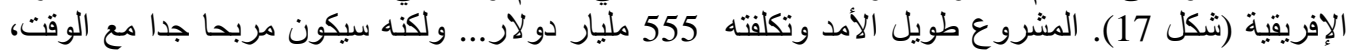

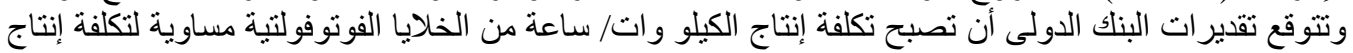

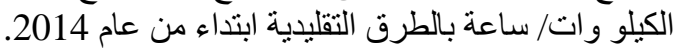

\section{7- مشروعات للحل (المنطقة العربية):}

هناك محاو لات عدة تقوم بها بعض الدول العربية لتوليد الطاقة من مصادر متجددة وفيما يلي بعضا منها.

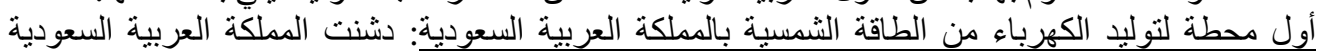

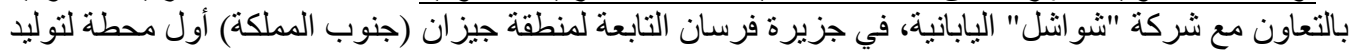

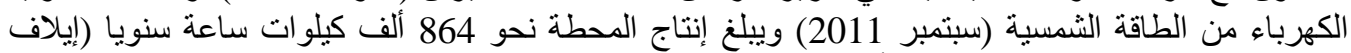
موباليل 18 ديسمبر الطياء 2011) شكل (18 أ).

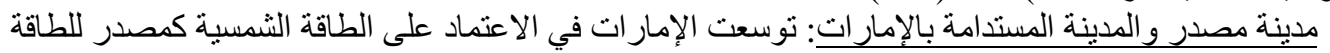

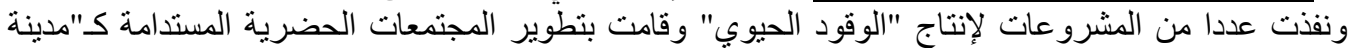

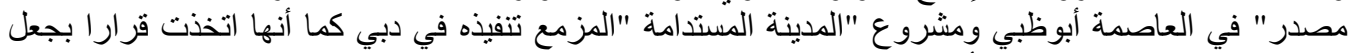

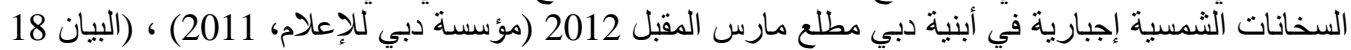

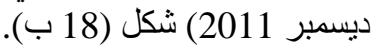

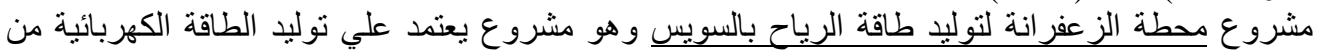

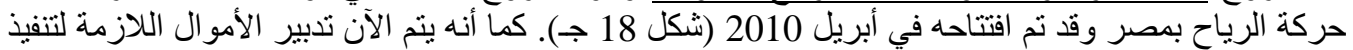

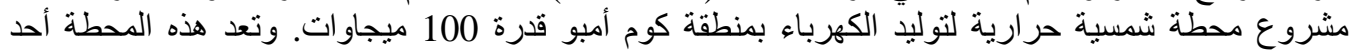

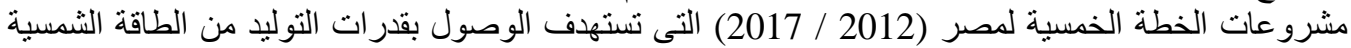

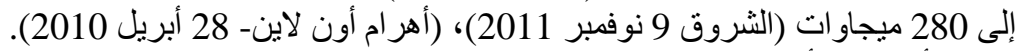

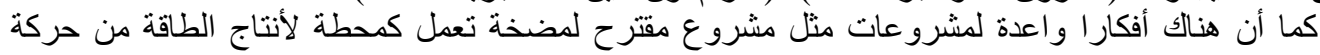

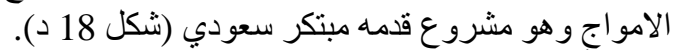

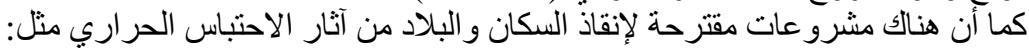

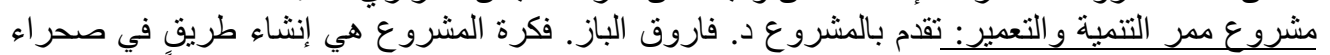

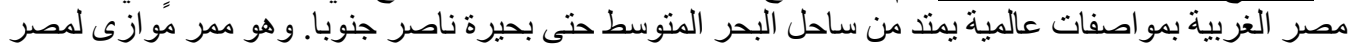

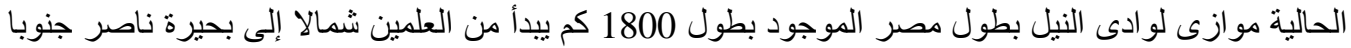

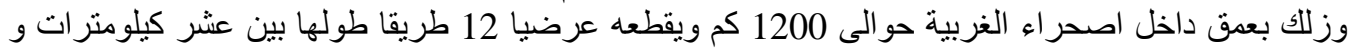

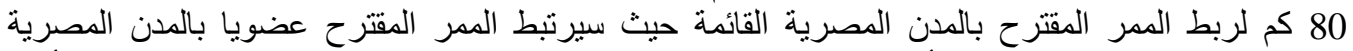

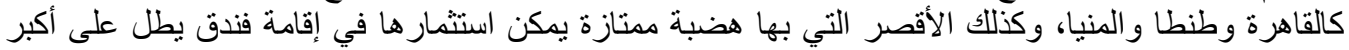

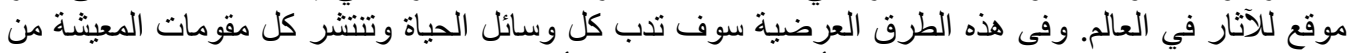

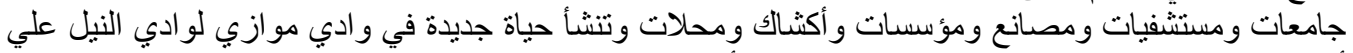

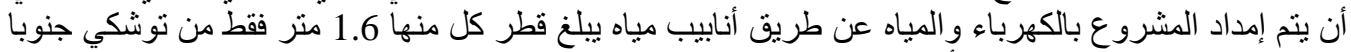

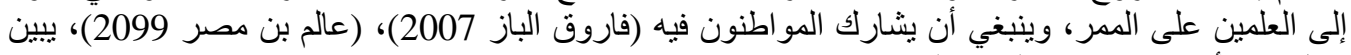

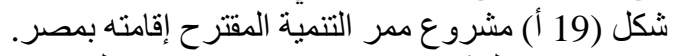

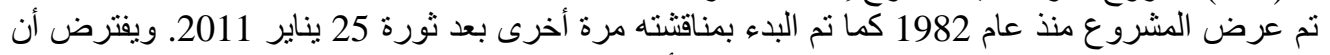

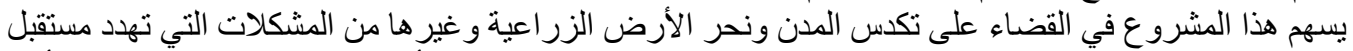

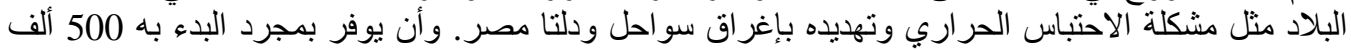

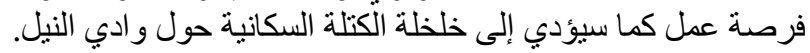




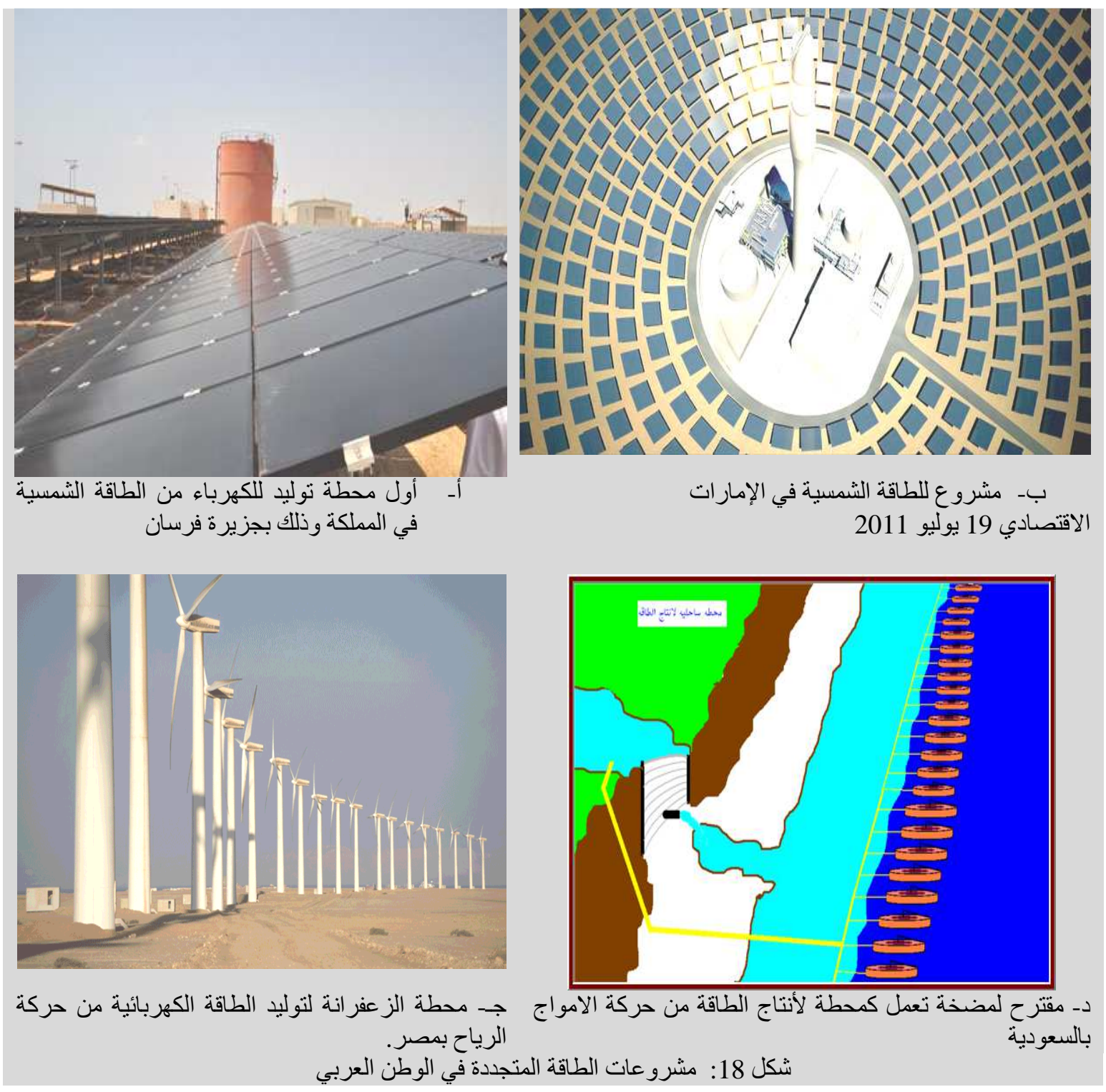

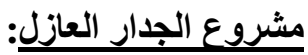

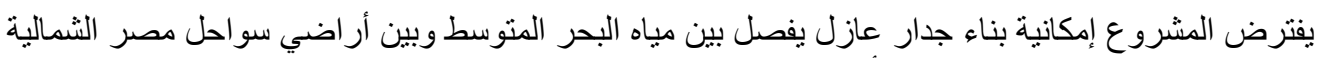

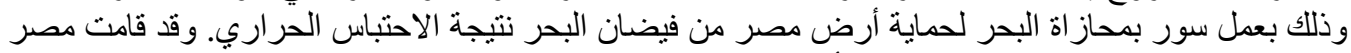

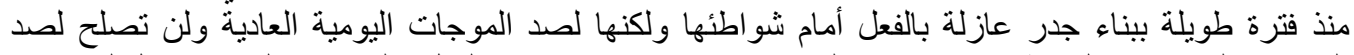

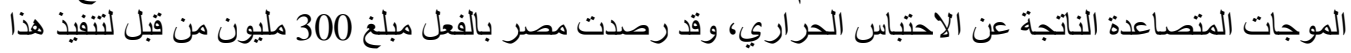

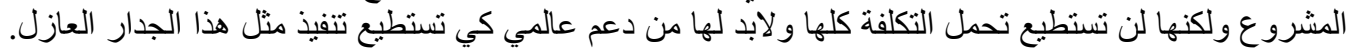
يوضح شكل (19 ب) الجدار المقترح إقامته لحماية سو احل مصر الثمالية من ارتفاع مستوى مياه البحر نتيجة الاحتباس الحراري (IRIN, 2011). 


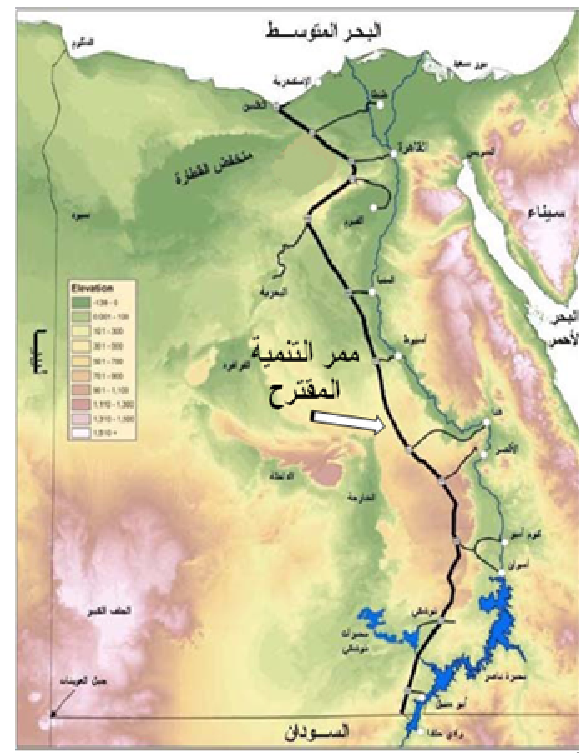

أـ- مشروع مدر التتمبة المقترح إقامته بمصر

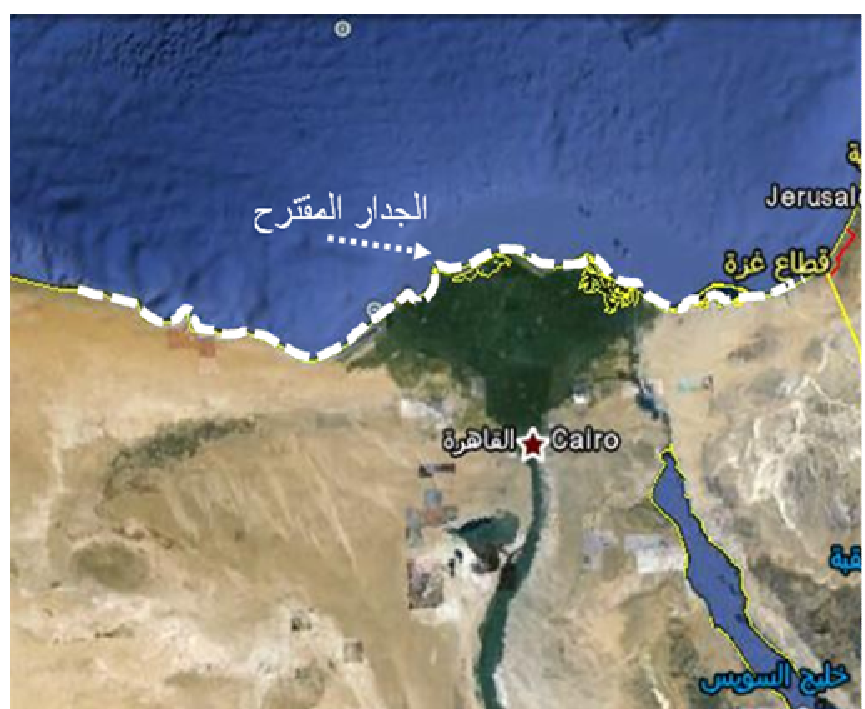

بـ مشروع الجدار العازل المقترح إقامته لحماية سو احل مصر الثمالية

(El-Baz)

شكل 19: مشروعات للتغلب علي آثار الاحتباس الحراري في مصر

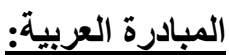

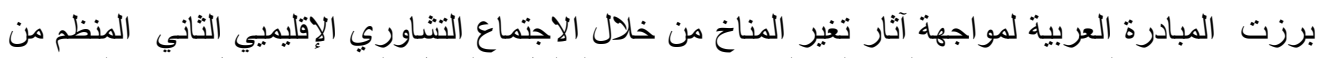

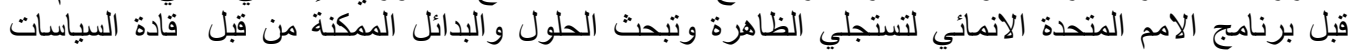

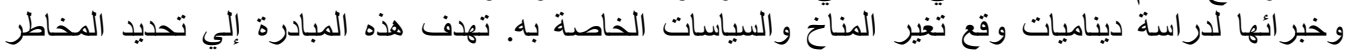

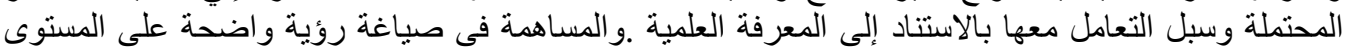

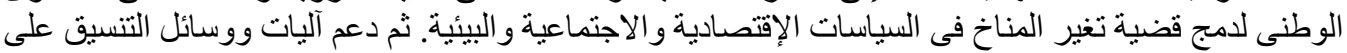

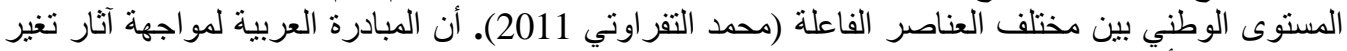

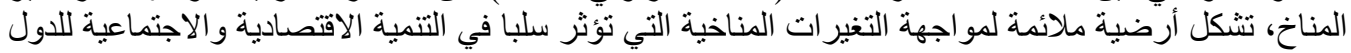

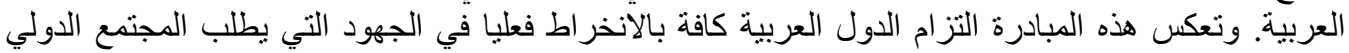

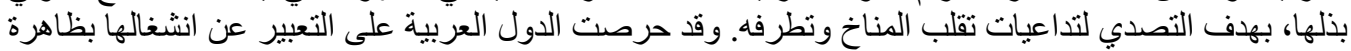

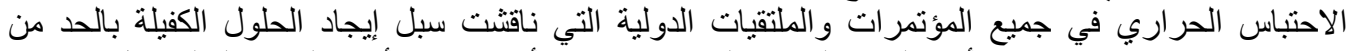

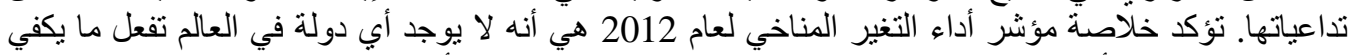

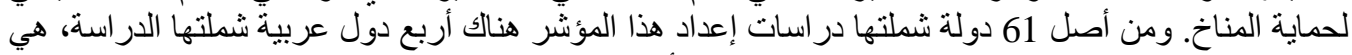

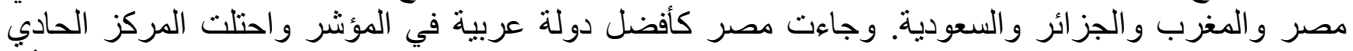

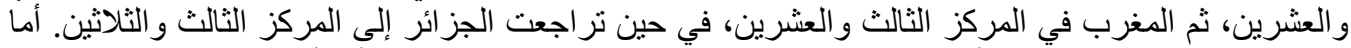

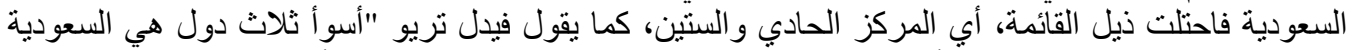

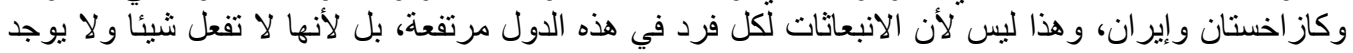

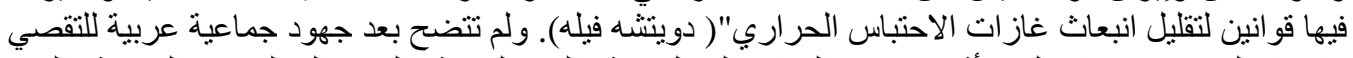

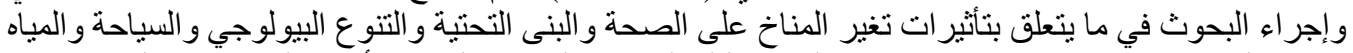

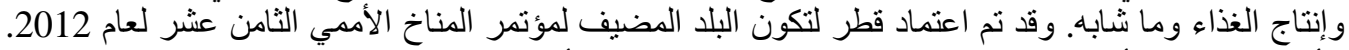

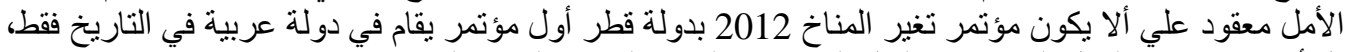

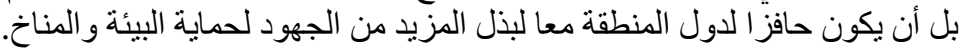

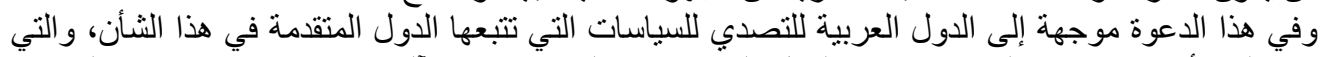

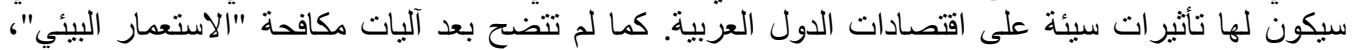

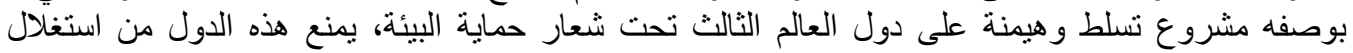




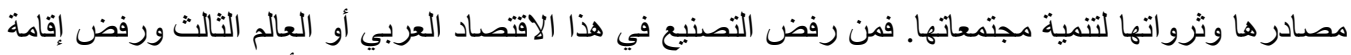

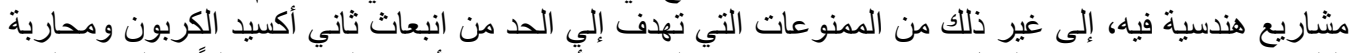

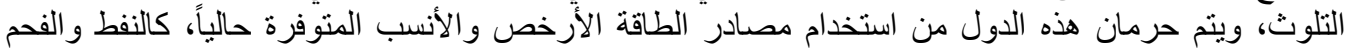

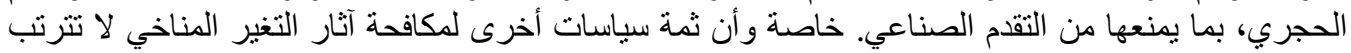

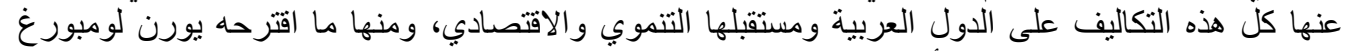
Lomborg Bjorn

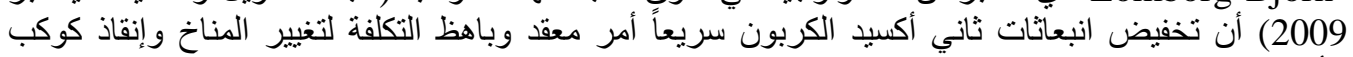

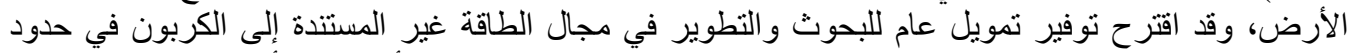

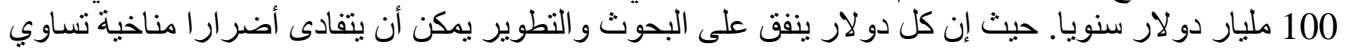

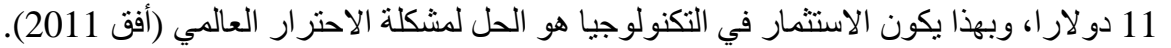

\section{8- التوصيات:}

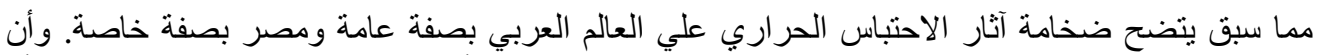

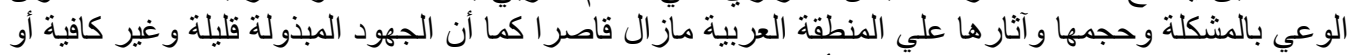

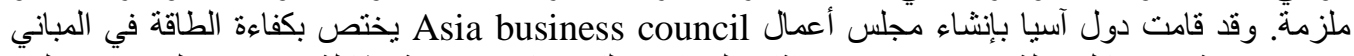

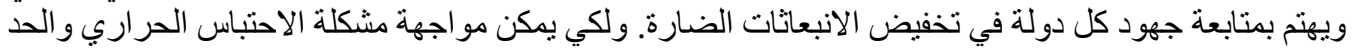

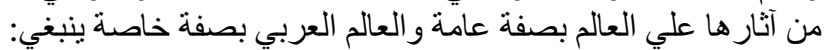

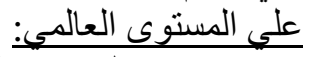

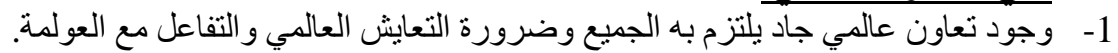

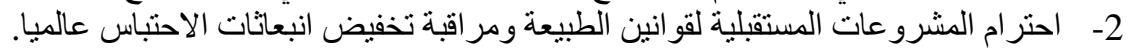
علي المستوى العربي:

3- إنشاء مجلس أعمال عربي يختص العبد بكفاءة الطاقة في المباني ومتابعة جهود الدول العربية في تخفيض الانبعانات الضارة.

4- التأكيد علي ضرورة التبات معاونة الدول المتقدة للدول النامية في التغلب علي آتار الاحتباس الحراري.

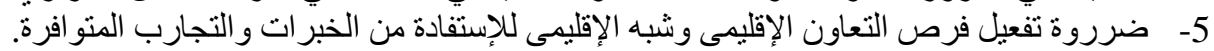

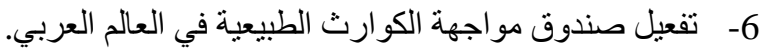

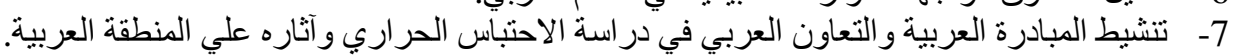

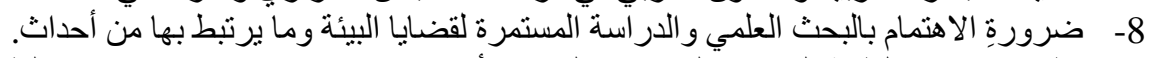

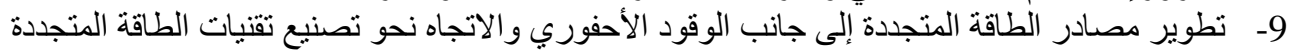

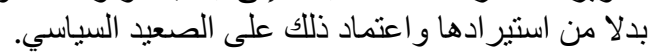

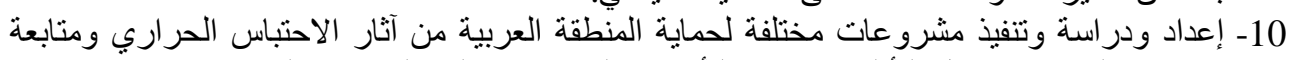

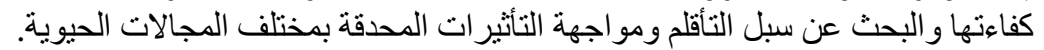

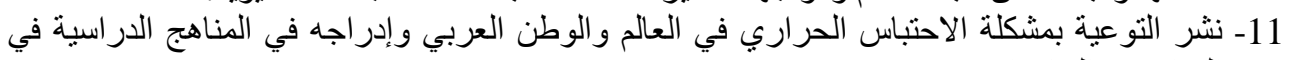
المدارس و الجامعات.

12- ضرورة الاستفادة من جميع الكوادر في جميع التخصصات والجهود الذاتية للمواطنين أيضا لمواجهة هذه المشكلة.

13- تفعيل الإستفادة من الخبرة العالمية والمساهمة في صياغة إطار يسمح بنقل التكنولوجيا الملائمة لاحتياجات الأول العربية.

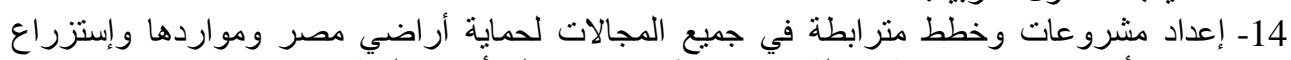

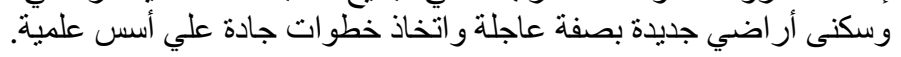

\section{9- المضمون:}

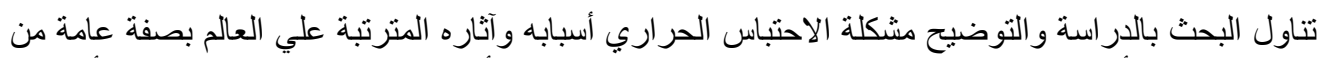

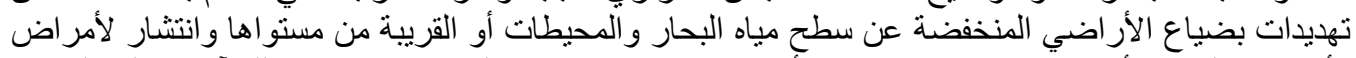

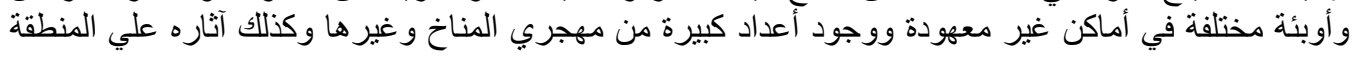


العربية بصفة خاصة وتهديدات بغرق سواحل طويلة فيها ودلتا النيل في مصر تحت مياه البحار و المحيط و الخليج

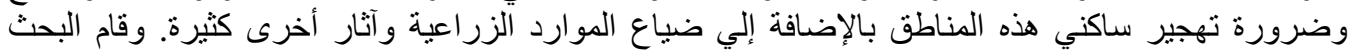

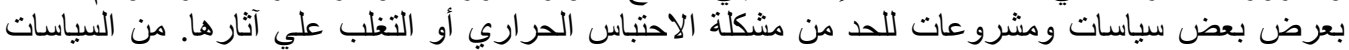

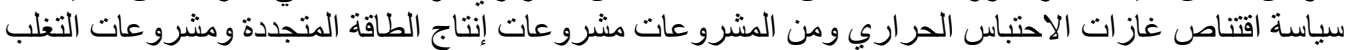

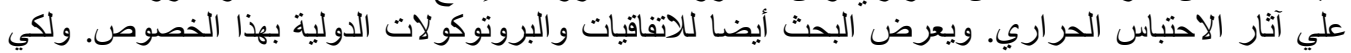

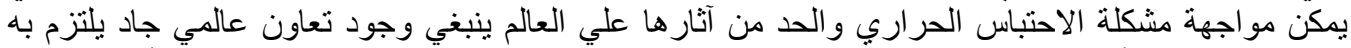

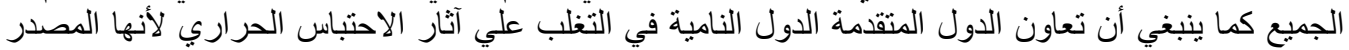

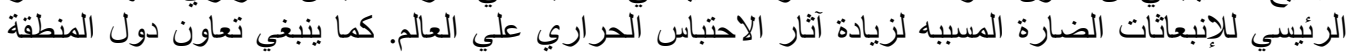

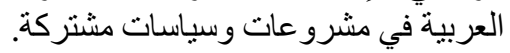

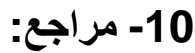

أبو كريץ: البحير ات القاتلة، منتدى الكوارث - 2008 / 12 / 25 http://www.isdm.gov.sa/forum/showthread.php?t=373

أفق 2011: هل نحن بصدد إرهاب بيئي؟ أفق: مجلة الكترونية تصدر عن مؤسسة الفكر العربي. العدد :

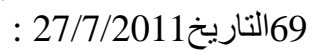

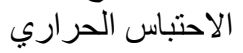

http://www.egyptsons.com/misr/showthread.php?t=75733

الإمار ات بين أكثر دول العالم اهتماماً بقطاع الطاقة المتجددة. مؤسسة دبي للإعلام 19 يوليو 2011.

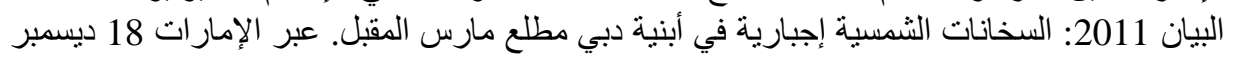
2011. مؤسسة دبي للإعلام. http://www.albayan.ae/across-the-uae/news-and-reports/2011-12-06-1.1550103 http://www.albayan.ae/economy/local-market/2011-07-19-1.1474313

المؤتمرنت: لاحتباس الحراري يهدد مصر بكارثة. 1 سبتمبر 2007.

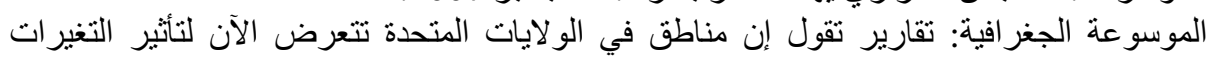
المناخية، 10 مارس

http://www.4geography.com/vb/showthread.php?t=1894Center for climate and energy solutions

أهر ام أونلاين: افتتاح محطة الزعفر انة لتوليد طاقة الرياح بالسويس. جريدة الأهر ام أونلاين 2 أكتوبر 2011

http://www.ahram.org.eg/Egypt/News/17855.aspx

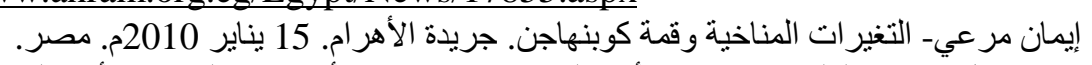

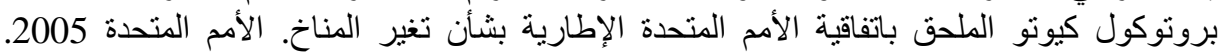

A) GE.05-61644 070605070605 (FCCC/INFORMAL/83 بلقيس عثمان العثا: رسم خريطة تهديدات تغير المناخ - تأثيرات التنمية الإنسانية في البلدان العربيةـ برنامج الأمم المتحدة الإنمائي ـ المكتب الإقليمي للأول العربية ـ تقرير التنمية الإنسانية 2010.

$$
\text { بو ابة عمل منظومة الأمم المتحدة في مجال تغير المناخ }
$$

http://www.un.org/ar/climatechange/the-un-climate-change-convention-andthe-kyoto-protocol.shtml

تقارير للبنك الدولي و الخبراء يحذرون: ارتفاع منسوب المياه يهدد بغرق الإسكندرية وربع الدلتا ومصر

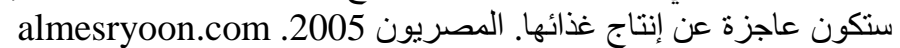
تقرير عن التنمية في العالم 2010- عرض عاء عام مسبقـ التنمية وتغير المناخ. البنك الدولي للإنشاء و التعمير 2009.

دويتشه فيله: خبراء المناخ يحذرون ممن احتباس حراري أسوأ من المتوقع. علوم وتكنولوجيا http://www.dw-world.de/dw/article/0,,4928853,00.html .25.11.2009 
دويتشه فيله: مؤشر المناخ: مصر الأفضل عربيا والسعودية في ذيل القائمة. 1693012.2011. http://www.dw-world.de/dw/article/9799/0,215599304,00.html

زايد السريع: السعودية للكهرباء تدشّن أول محطة طاقة شمسية بتعاون ياباني. إيلاف 2 أكتوبر 2011. http://www.elaph.com/Web/Economics/2011/10/686676.html

سعودى يبتكر مضخه تستخدم الموج كمولد للطاقة الكهربية http://www.mawhopon.net/ver ar/news.php?news id=4936

سفيان التل: الاحتباس الحراري. مسلم أونلاين 22 شباط 2009

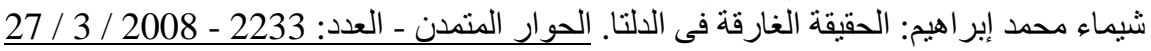
http://www.ahewar.org/debat/show.art.asp?aid=129472

فاروق الباز: مشروع ممر التعمير الغربي يتحول إلى واقعٍ ملموسٍ قريبًا. إخوان أون لاين 20022007/10/23.

http://www.egyptsons.com/misr/showthread.php?t=74147

مالسبب ور اء تغير مناخ الأرض:

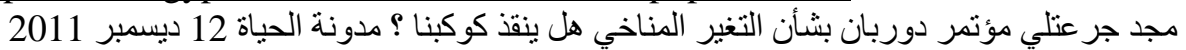
http://kawngroup.com/ar/energy-n-environment/2010-07-04-23-45-11/88kyoto-protocol

محمد التفر اوتي: المبادرةُ العربيّة لمواجهة آثار تَغيُر المناخ. البيئة الآن. 10/1/2010. http://www.ennow.net/?browser=view_article \&ID=581\&lang=0\&loac=0\&sect ion $=15 \&$ supsection $=\&$ file $=0 \&$ keyword $=$

محمد الثرقي: المنطقة العربية مهدة بظاهرة الاحتباس الحراري. الثبكة العربية للتنمية المجتمعية،

.11-15-2010

http://www.ydbyd.net/dar/showthread.php?p=3130

منصور المحارب: الدول العربية ستكون من أكثر المناطق المتأثرة بظاهرة الاحتباس الحراري. جريدة الأبراج 2008-22-11.

http://www.alabraj.org/NewsDetails.aspx?NewsID=7039

منال البطران: اثر تغير المناخ على مصر وبخاصة على الهجرة الداخلية و الخارجية. مؤتمر تغير

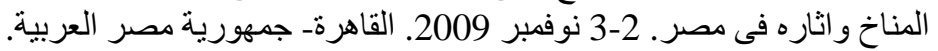

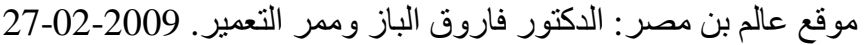

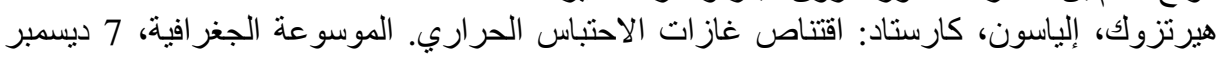
2009

http://www.4geography.com/vb/showthread.php?t=983

- Asia business council book, 2007: building energy efficiency- why green building are key to Asia's future.

- Costa Rica and Global Warming One of the predicted safe countries. Costa Rica travel network 1997.

http://www.orbitcostarica.com/global_warming.html

- Deborah Phelan (2011) " Egypt's Next Crisis: Climate Change \& Justice -"We are Egypt!", Climate Change: The Next Generation, January 30, 2011.

- http://climatechangepsychology.blogspot.com/2011 0101 archive.html

- Dennis Newman: Global Warming: Oregon May Be Hit Hardest By Rising Sea Levels

http://www.naturaloregon.org/2009/02/05/global-warming-oregon-may-be-hithardest-by-rising-sea-levels/ 
- DREF, 2010 "The International Federation's Disaster Relief Emergency Fund" (DREF), DREF operation $n^{\circ}$ MDREG009 GLIDE $n^{\circ}$ FL-2010-000012-EGY, 21 January 2010

- Farouk El-Baz, Ted A. Maxwell, Ibrahim Hassan Himida \& Samy Soliman Mohammed, (Egypt: Groundwater Exploration in the Sahara Desert", center of remote sensing. http://www.bu.edu/remotesensing/research/completed/saharagroundwater/

- FluTrackers.com (2010) "Extreme, Unusual Rain Aimed for Egypt", FluTrackers.com, January 17th, 2010 http://www.flutrackers.com/forum/showthread.php? $\mathrm{p}=336678$

- Global warming truth: Unofficial transcription of 'An Inconvenient Truth'-Part 2. Global Warming Truth-Home » Environmental-tv-movies ». http://www.global-warming-truth.com/environmental-tv-movies/unofficialtranscription-of-an-inconvenient-truth-part-2.html

- IRIN (2011) " EGYPT Disaster looms for Delta region", the humanitarian news and analysis service of the UN Office for the Coordination of Humanitarian Affairs, CAIRO, 7 October 2009 (IRIN), 18 June 2011.

http://www.irinnews.org/Report.aspx?ReportId=86472

- IPCC (2007) "Climate Change 2007: Working Group II: Impacts, Adaption and Vulnerability", IPCC Fourth Assessment Report: Climate Change 2007, IPCC Intergovernmental panel for climate change http://www.ipcc.ch/publications_and_data/ar4/wg2/en/ch9s9-4-4.html

- Jacqueline Karas " climate change and the Mediterranean region", http://www.greenpeace.org/raw/content/international/press/reports/climatechange-and-the-mediter.pdf

- Jim Andrews (2010) " Extreme, Unusual Rain Aimed for Egypt", AccuWeather.com, Jan 16, 2010 http://www.accuweather.com/blogs/andrews/story/23777/extreme unusual rai n_aimed_for_egypt.asp

- MICHAEL COTE (2011), Egypt Is Extremely Vulnerable to Climate Changes: Could a New Government Help the Country Adapt?, Environment, February 3, 2011

http://www.good.is/post/egypt-is-extremely-vulnerable-to-climate-impactshow-could-a-new-government-help-the-country-adapt/

- Mohamed El-Raey; Dia H.El-Quosy; Mahmoud El-Shaer; Osama A.El Kholy; Ayat Soliman (1995) " Egypt: Inventory and Mitigation Options,and Vulnerability and Adaptation Assessment", CSP interim report on climate change country studies, March 1995.

- Mostafa K. Tolba; Najib W. Saab, (2009), Arab environment climate changeImpact of climate change on Arab countries, 2009 report of the Arab forum for environment and development.

- Paroma Basu: Third World bears brunt of global warming impacts. the University of Wisconsin Madison news, 16 November 2005. http://www.news.wisc.edu/11878

- study of environmental assessment for $\mathrm{CO} 2$ Ocean sequestration for mitigation of climate change 
http://www.rite.or.jp/English/lab/ocean/intoro/about 02.html

- The Great Ocean Conveyer Belt. The Environmental Literacy Council, 2002.

- http://www.enviroliteracy.org/article.php/545.html.

- What is Global Warming?, Tropical-Rainforest-Animals.com 2008-2012

- Google Earth http://flood.firetree.net/?ll=27.2839,-80.7275\&z=10\&m=14\&t=1

- http://www.ahram.org.eg/Egypt/News/17855.aspx

- http://inhabitat.com/ginormous-saharan-renewable-project-moving-forward/ 